\title{
Seismic behavior of precast reinforced concrete column-to-foundation grouted duct connections
}

\author{
Lorenzo Hofer $^{1}$ - Mariano Angelo Zanini ${ }^{1}$ (D) . Flora Faleschini ${ }^{1} \cdot$ Klajdi Toska $^{1}$. \\ Carlo Pellegrino ${ }^{1}$
}

Received: 8 December 2020 / Accepted: 20 May 2021 / Published online: 1 July 2021

(c) The Author(s) 2021

\begin{abstract}
The paper shows the results of an experimental campaign aimed at investigating the cyclic behavior of a column-to-foundation joint for precast concrete elements. The tested connection is realized adopting corrugated steel ducts embedded into the foundation, in which column protruding rebars are anchored by grouting high performance mortar. The experimental program consists in testing six full-scale reinforced concrete square-section columns subject to quasi-static cyclic lateral load with a constant axial compression. A preliminary series of bond tests was carried out to define some experimental variables, i.e., longitudinal rebar diameter and anchorage length. Results of the precast joints are compared with those of two reference cast-in-place specimens with the same geometric characteristics, showing similar hysteretic behavior, energy dissipation and ductility values. Lastly, the plastic hinge height is computed for all the specimens based on experimental concrete strains, and compared to current codes formulations.
\end{abstract}

Keywords Precast concrete column · Column-to-foundation connection · Grouted duct connection $\cdot$ Cyclic test $\cdot$ Seismic behavior

\section{Introduction}

Precast structures are widely diffused structural typologies since they allow minimizing the on-site construction time and cover wide open spaces. Hence, precast concrete structures have been widely adopted to realize industrial plants, factories and warehouses (Buratti et al. 2017). Typically, the configuration of these structures is simple, consisting in cantilever columns connected with simply supported beams. Consequently, the structural behavior of the connections strongly influences the overall structural response of this structural type (Elliot 2017). Indeed, when precast frame structures are subject to horizontal forces, the ductility demand is concentrated at the base of the column, which becomes the most critical part of the structure.

Mariano Angelo Zanini

marianoangelo.zanini@dicea.unipd.it

1 Department of Civil, Environmental and Architectural Engineering, University of Padova, Padova, Italy 
Past earthquake events clearly highlighted the main deficiencies of precast industrial buildings, which include the low performance of the connections between structural elements under seismic actions (Yanev 1989; Sezen and Whittaker 2006). Recent examples of such damage type can be found in the damage surveys from the 2012 Emilia earthquake in Italy, that struck a high industrialized area of the country, affecting many precast buildings (Belleri et al. 2015; Minghini et al. 2016; Savoia et al. 2017). This event has also highlighted how earthquake damage in industrial plants and warehouses may have indirect consequences, such as losses due to business interruption, with the same or greater extent than direct damage on the structures (Hofer et al. 2018; Nocera and Gardoni 2019; Caputo et al. 2020). For these reasons, connections play a key role in precast buildings, and their correct design has a great importance to realize earthquake resistant structures (Negro and Toniolo 2012). Basically, they have to ensure an overall strength, ductility and dissipation comparable with those of the common cast-in-place (CIP) connections.

In last decades, many connection types have been developed and tested, and can be summarized in two categories: (I) traditional column-to-foundation connections, where the entire column is inserted into a pocket foundation, (II) connections aimed to connect directly the column's longitudinal bars or the bottom of the column to the foundation. In the latter case, two main approaches have been developed: (IIa) connections adopting bar couplers or bolted connections, and (IIb) connections exploiting high performance mortar, grouted in corrugated ducts.

As regards pocket foundations (I), the temporary bearing and the vertical alignment is ensured by the crane and by provisional props. Once positioned, the joint is filled with insitu concrete pouring. The efficiency and effectiveness of this technology have been investigated with extensive experimental tests by Saisi and Toniolo (1998), and more recently by Zhang et al. (2021) and Xu et al. (2021). It is worth to mention how typically such solution implies large excavations and difficult transportation, particularly when large column size is used.

In recent years, scientific research focused mainly on the second type of connections (II), aiming to develop technological systems able to facilitate and speed up the on-site assembly. Concerning the group of connections IIa, mechanical bar couplers for connecting the reinforcement bars at the base of the column were tested by Philippi and Hegemier (2013), that showed how the compression region of the column became unstable due to the buckling of the steel reinforcement around the location of the couplers. Two other couplers configurations, i.e. upset headed coupler and a grout-filled sleeve coupler, were investigated by Haber et al. (2012). In the experimental campaign, the authors varied also the location of couplers within the plastic hinge zone, showing how the behavior of the new connections was similar to that of conventional CIP construction in terms of key response parameters, although the plastic hinge mechanism was negatively affected by the couplers disposition. Similar experimental campaigns were conducted also by Liu et al. 2020 and Wang et al. 2021. More recently Al-Jelawy et al. (2017), developed new construction details for grouted splices connections located in the column, for improving the element displacement ductility. For sake of completeness, also the works of Liu et al. (2018) and Guo et al. (2020) should be mentioned, where authors adopted bars' couplers grouted with mortar.

Dal Lago et al. (2016) presented a comparison of the structural behavior of four different mechanical column-foundation connections devices that can be included in the IIa category since they adopt a bolted mechanical connection. These connections are named: (i) post-screwed protruding bars, (ii) standard bolted socket, (iii) overturned bolted sockets and (iv) bars' threaded couplers. The first solution $(i)$ is similar to that tested in this work, 
apart that the protruding bar are post-screwed to the bottom of the column by steel double threaded sockets. Such solution showed a stable hysteretic behavior, even if the discontinuity of the threaded socket highlighted a weak point in the longitudinal bar, where damage has concentrated. In the second solution (ii), protruding bar anchors were embedded in the foundation and anchored to the column's base using standard bolted sockets directly welded to the reinforcing bars of the column. The gap between the column and the foundation was subsequently filled with high performance mortar. A similar connection was tested by Fagà et al. (2010) and Camnasio et al. (2017). This solution displayed high pinching effect in the hysteretic behavior, with an overall low energy dissipation capacity. The third solution (iii) is a modification of the standard bolted socket, in which the socket is overturned and inserted into the foundation, with the last $50 \mathrm{~mm}$ protruding from it. This connection type showed a cyclic response similar to (ii), but with a slightly higher energy dissipation capacity. Lastly, the fourth connection solution (iv) consisting in two thick steel plates assembled together with high resistance bolts is characterized by an overall good ductility, but a low energy dissipation with a pinched behavior.

The last approach deals with the use of grouted duct connections (IIb) for connecting precast elements, where reinforcement bars protruding from one precast unit are grouted into corrugated steel ducts encased in the other unit, usually with high performance mortar. This technology has been mainly applied for column-to-column and column-to-foundation connections. Regarding applications in column-to column connections, Zheng (1996) investigated the behavior of a dowelled and grouted precast concrete column connection, under reversed and cyclic bending combined with axial compression. Results showed that a full anchorage of the dowels was achieved with this technique, and that the ultimate strength can be computed using conventional reinforced concrete (RC) beam theory. However, the monolithic column appeared to be more ductile than the precast ones at the ultimate condition. Recently, Tullini and Minghini (2016) tested column-to-column connections: they carried out three monotonic tests (axial tension and four-point bending with and without axial compression) and to two cyclic tests (four-point bending and shear). In the monotonic bending test, the authors observed a significant enhancement in strength, while in the shear test failure occurred due to achieving the pure shear capacity of the bars crossing the joint. The cyclic bending test showed a ductile and stable hysteretic behavior of the connected members with proposed method. Concerning column-to-foundation connections, solutions with longitudinal bars protruding from the foundations and anchored in the column and viceversa (i.e., from the columns to the foundations) were analyzed in literature. While the former connection was tested in several experimental campaigns (Belleri and Riva 2012; Popa et al. 2015; Tullini and Minghini 2020; Seifi et al. 2019; Fan et al. 2020), the latter was little investigated. In 2012, Buratti et al. tested one column with protruding rebars anchored in the foundations by grouted ducts, showing its overall satisfying behavior. However, the steel tube used to center the column, influenced the column behavior, increasing the stiffness and the strength of the base section and shifting up the critical section.

The above context highlights the necessity to enlarge the current knowledge on this latter type of connection, i.e. with protruding bars from the column to be grouted in the ducts placed in the foundation, since an extended experimental campaign on this regard is currently lacking. Hence, in the present study six real scale column-to-foundation prototypes were experimentally tested, investigating the influence of two parameters: the longitudinal bar diameter and the anchorage length. Three specimens were reinforced with the lowest steel bar diameter $\left(d_{b 1}=24 \mathrm{~mm}\right)$ and three with the highest $\left(d_{b 2}=30 \mathrm{~mm}\right)$. For each triplet, one specimen was realized adopting CIP design, and two adopt the analyzed connection for precast 
elements. In this last case, two anchorage length $\left(a_{L}\right)$ values $\left(a_{L 1}=26 \cdot d_{b} ; a_{L 2}=17 \cdot d_{b}\right)$ were used, which values were chosen based on a preliminary set of pull-out tests, described in this work too. The manuscript is organized as follows: Sect. 2 deals with the pull-out testing campaign aimed at assessing the optimal anchorage length in grouted duct connection system; Sect. 3 describes in detail the experimental campaign carried out on the full-scale foundationto-column connection specimens illustrating specimens geometries, material properties, fabrication process and testing set-up. Lastly, Sect. 4 shows the main results and discussion on the applicability of current code provisions to properly estimate the plastic hinge length for members designed with this technology.

\section{Influence of embedement length on bond behavior}

A preliminary experimental campaign was carried out for estimating anchorage length values to be adopted in the full-scale column-to-foundation specimens. Indeed, despite the growing use of this technology, few research works studied bond of reinforcement in grouted duct connections (Einea et al. 1995; Matsumoto et al. 2008; Elsayed and Nehdi 2017; Elsayed et al. 2018a; Elsayed et al. 2018b, Zhou et al. 2017). Hence, a series of pullout test were performed, both on grouted duct connection and reference specimens, these latter realized with reinforcing bars directly embedded in concrete (i.e., as in the cast-inplace solution).

The first variable of the experimental program is the steel reinforcement diameter bar $\left(d_{b}\right)$ : two diameters were analyzed (i.e., $d_{b 1}=24 \mathrm{~mm}$ and $d_{b 2}=30 \mathrm{~mm}$ ), being among those mostly adopted in precast structures. Grouted specimens were realized with both the diameter bars, whereas only $24 \mathrm{~mm}$ reinforcing bars were used to cast reference samples. The second variable is the anchorage length $\left(a_{L}\right)$. For grouted specimens with $24 \mathrm{~mm}$ bars, five $a_{L}$ values were analyzed, being $10,14,17,22$ and $26 \cdot d_{b 1}$ (i.e., ranging between 240 and $624 \mathrm{~mm}$ ). Instead, for grouted specimens with $30 \mathrm{~mm}$ rebars, only the three highest values of $a_{L}$ were analyzed, being 17, 22 and $26 \cdot d_{b 2}$ (i.e., ranging between 510 and 780 $\mathrm{mm}$ ). Lastly, for the reference specimens with $24 \mathrm{~mm}$ steel bars, two $a_{L}$ values were tested, equal to 22 and $26 \cdot d_{b 1}$ (i.e., 528 and $624 \mathrm{~mm}$ ). For each configuration, three specimens were tested. Figure 1 shows the geometry of all the tested samples. Note that every specimen presents two de-bonded regions of $2 \cdot d_{b}$ length at each lateral face, as recommended by Elsayed and Nehdi (2017), Elsayed et al. (2018a, b), RILEM (1982) and RILEM (1983), to avoid local failure.

Concerning materials properties, they are listed in Table 1: for each property, at least three specimens were used at the time of pull-out tests. A C25/30 concrete strength class was used for all the samples (EC2 2014), i.e., with cylindrical and cube characteristic compressive strength of $f_{c k}=25 \mathrm{MPa}$ and $f_{c k, c u b e}=30 \mathrm{MPa}$, respectively. This choice is motivated by the need of using the same concrete class commonly adopted in the construction practice for foundations. However, specimens were realized with different batches, and thus compressive $\left(f_{c, \text { cube }}\right)$ and tensile $\left(f_{t}\right)$ strength values of each of them is reported in Table 1. In the same table, compressive $\left(f_{c, \text { cube }}\right)$ and flexural strength $\left(f_{f}\right)$ values of the grout, a highperformance and shrinkage-compensating mortar, evaluated on $40 \times 40 \times 160 \mathrm{~mm}$ prisms according to EN 1015 series, were listed. The steel reinforcement is made up of bars of B 450C class (characteristic yielding strength $f_{y k}=450 \mathrm{MPa}$; ultimate tensile strength $f_{t k}=$ $540 \mathrm{MPa}$; elastic modulus $\mathrm{E}=210 \mathrm{GPa}$ ), as prescribed by the Italian Code for Construction (NTC 2018). Lastly, the corrugated ducts adopted are typical post-tensioning ducts, made 
(a) $d_{b 1}=24 \mathrm{~mm}$
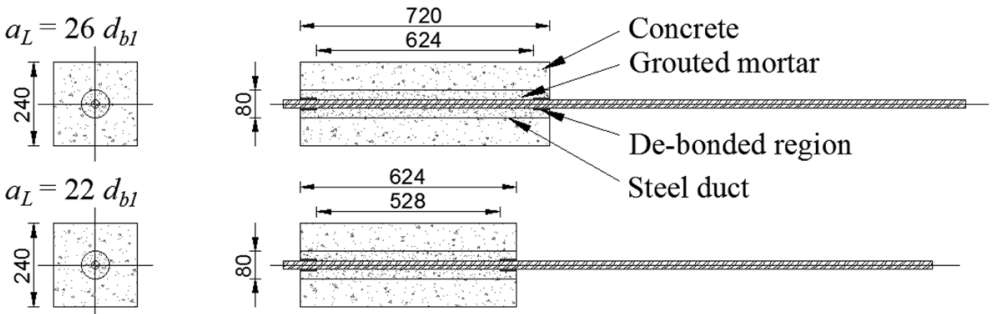

$a_{L}=22 d_{b 1}$

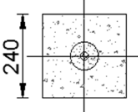

$a_{L}=17 d_{b 1}$
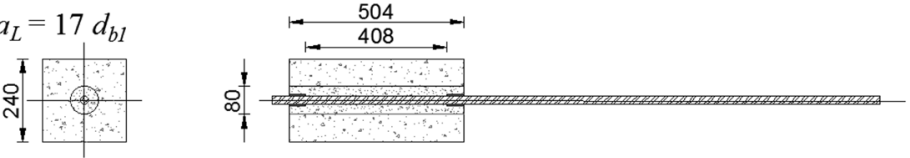

$a_{L}=14 d_{b 1}$
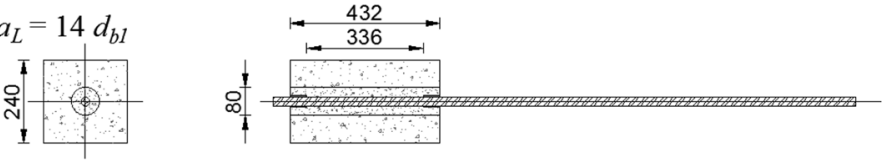

$a_{L}=10 d_{b 1}$
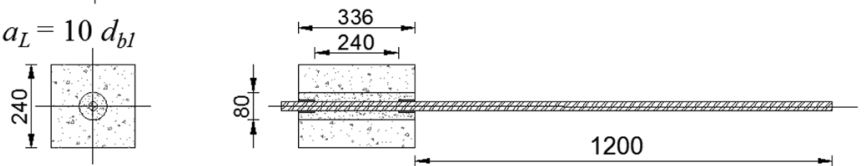

(b) $d_{b 2}=30 \mathrm{~mm}$
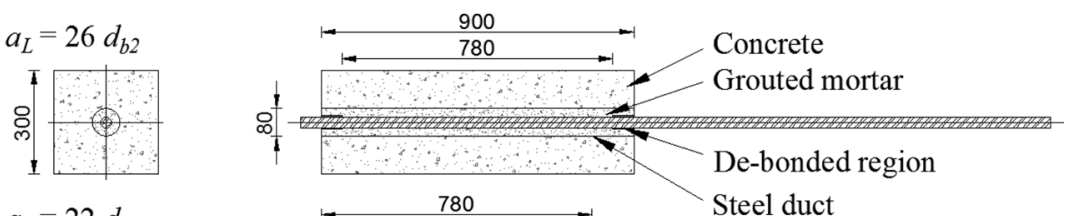

$a_{L}=22 d_{b 2}$
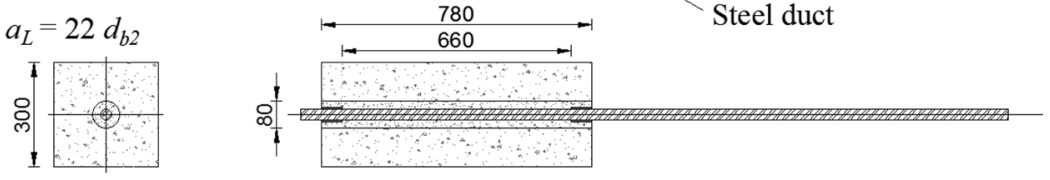

$a_{L}=17 d_{b 2}$
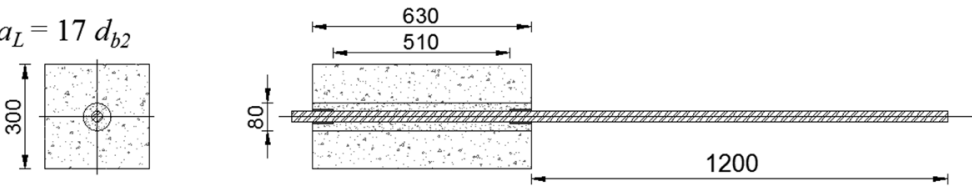

(c) $d_{b l}=24 \mathrm{~mm}$
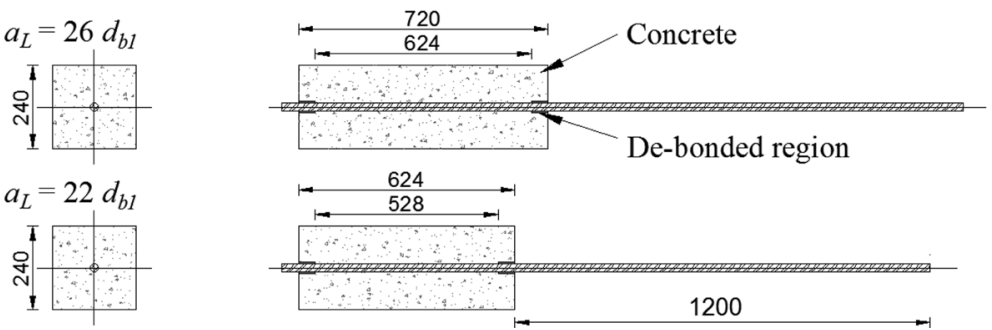

Fig. 1 Geometry of the pull-out specimens: a with grouted duct and $d_{b l}=24 \mathrm{~mm}$, b with grouted duct and $d_{b 2}=24 \mathrm{~mm}$ and $\mathbf{c}$ made of concrete only and $d_{b 1}=24 \mathrm{~mm}$ (dimensions are in [mm]) 
Table 1 Mechanical properties of the materials used in the pull-out specimens

\begin{tabular}{|c|c|c|c|c|c|}
\hline \multirow{3}{*}{$\begin{array}{l}\text { Anchorage } \\
\text { length } \\
a_{L}\end{array}$} & \multicolumn{4}{|l|}{ Grouted duct } & \multirow{3}{*}{$\begin{array}{l}\text { Reference } \\
d_{b 1}=24 \mathrm{~mm} \\
26 \cdot d_{b 1} \text { and } 22 \cdot d_{b 1}\end{array}$} \\
\hline & \multicolumn{3}{|l|}{$d_{b l}=24 \mathrm{~mm}$} & \multirow{2}{*}{$\begin{array}{l}d_{b 2}=30 \mathrm{~mm} \\
26 \cdot d_{b 2}, 22 \cdot d_{b 2} \text { and } 17 \cdot d_{b 2}\end{array}$} & \\
\hline & $26 \cdot d_{b 1}$ and $22 \cdot d_{b 1}$ & $17 \cdot d_{b 1}$ and $14 \cdot d_{b 1}$ & $10 \cdot d_{b 1}$ & & \\
\hline \multicolumn{6}{|l|}{ Concrete } \\
\hline$f_{c, \text { cube }} \quad[\mathrm{MPa}]$ & 44.20 & 50.80 & 40.10 & 50.30 & 42.30 \\
\hline$f_{t} \quad[\mathrm{MPa}]$ & 4.16 & 3.44 & 4.08 & 4.28 & 3.83 \\
\hline \multicolumn{6}{|l|}{ Mortar } \\
\hline$f_{c, \text { cube }} \quad[\mathrm{MPa}]$ & 83.09 & 86.09 & 73.77 & 63.70 & - \\
\hline$[\mathrm{MPa}]$ & 7.55 & 7.15 & 7.41 & 7.16 & - \\
\hline
\end{tabular}

with corrugated galvanized strip steel with an $80 \mathrm{~mm}$ internal diameter, an $84 \mathrm{~mm}$ external diameter, and a $0.6 \mathrm{~mm}$ thickness.

After concrete casting, specimens were air-cured in the laboratory, without significant thermal excursions (in average, $\mathrm{T}=20 \pm 2{ }^{\circ} \mathrm{C}$ and $\mathrm{RH}=50 \pm 5 \%$ ), and then tested in a universal machine with a maximum capacity of $2000 \mathrm{kN}$. Figure 2 shows the testing layout: note that the steel bar is gripped by two steel jaws in the loading machine. A $5 \mathrm{~mm}$ thick rubber layer was inserted between the concrete face and the steel plate to ensure a uniform contact and to minimize friction effects. Load was applied by lifting the upper moving head of the machine at a rate of $1.5 \mathrm{~mm} / \mathrm{min}$. The loading protocol was established after some trials to evaluate the loading rate influence, starting from $0.5 \mathrm{~mm} / \mathrm{min}$, typically adopted in RILEM pull-out test (1982), up to $1.5 \mathrm{~mm} / \mathrm{min}$. Finally, a $25 \mathrm{~mm}$ linear-variable displacement transducer (LVDT) was placed on the protruding bar (unloaded end - at the top of the specimen) to record the relative slip between the bar and concrete.

Table 2 lists the results in terms of observed failure mode. In the grouted duct specimens with an embedment length between $26 \cdot d_{b}$ and $17 \cdot d_{b}$, tensile failure of the steel bar

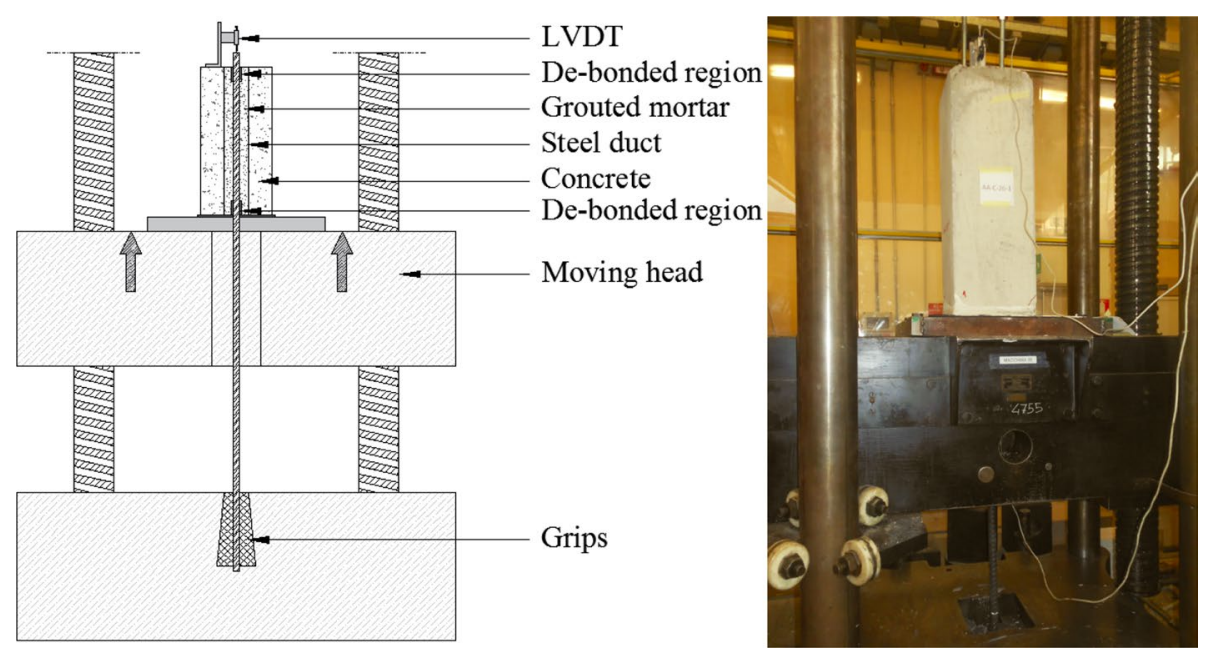

Fig. 2 Pull-out test setup and instrumentation 

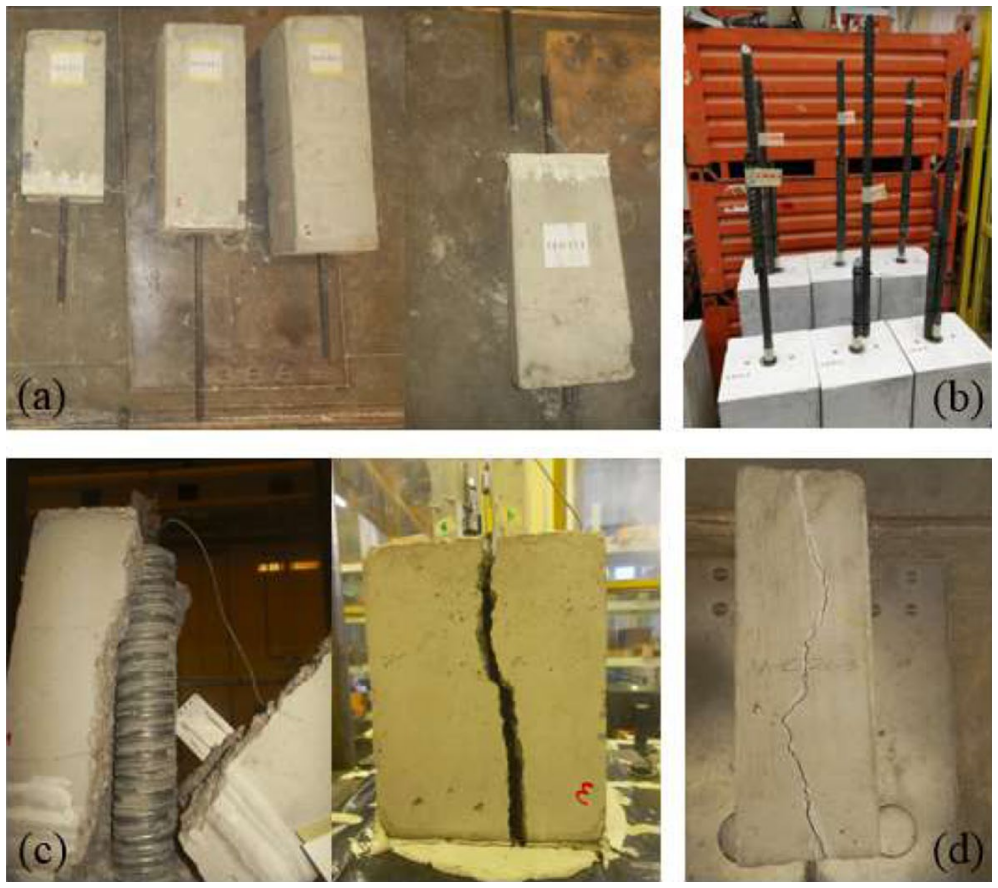

Fig. 3 Main failure mode observed in the pull-out test: a bar fracture for specimens with $d_{b l}$ and embedment length of $26 \cdot d_{b 1}, 22 \cdot d_{b 1}$ and $17 \cdot d_{b 1}$; $\mathbf{b}$ bar fracture for all the specimens with $d_{b 2}$ and $26 \cdot d_{b 2}, 22 \cdot d_{b 2}$ and $17 \cdot d_{b 2}$; $\mathbf{c}$ splitting failure for some specimens with $d_{b 1}$ and $14 \cdot d_{b l}, 10 \cdot d_{b 1}$; $\mathbf{d}$ splitting failure for reference specimens with $26 \cdot d_{b 1}$ and $22 \cdot d_{b 1}$

Table 2 Pull-out results: failure modes $(\mathrm{BF}=$ bar failure; $\mathrm{SY}=$ splitting with bar yielding; $\mathrm{S}=$ splitting without bar yielding)

\begin{tabular}{llll}
\hline $\begin{array}{l}\text { Grouted duct } \mathrm{d}_{b 1}= \\
24 \mathrm{~mm}\end{array}$ & Failure mode & Grouted duct $\mathrm{d}_{b 2}=30 \mathrm{~mm}$ & Failure mode \\
\hline $26 \cdot d_{b 1}$ & $3 \mathrm{BF}$ & $26 \cdot d_{b 2}$ & $3 \mathrm{BF}$ \\
$22 \cdot d_{b 1}$ & $3 \mathrm{BF}$ & $22 \cdot d_{b 2}$ & $3 \mathrm{BF}$ \\
$17 \cdot d_{b 1}$ & $3 \mathrm{BF}$ & $17 \cdot d_{b 2}$ & $3 \mathrm{BF}$ \\
$14 \cdot d_{b 1}$ & $2 \mathrm{BF}+1 \mathrm{SY}$ & Concrete only $\mathrm{d}_{b 1}=24 \mathrm{~mm}$ & Failure mode \\
$10 \cdot d_{b 1}$ & $1 \mathrm{BF}+2 \mathrm{SY}$ & $26 \cdot d_{b 1}$ & $2 \mathrm{BF}+1 \mathrm{SY}$ \\
& & $22 \cdot d_{b 1}$ & $1 \mathrm{BF}+1 \mathrm{SY}+1 \mathrm{~S}$ \\
\hline
\end{tabular}

occurred, for both the investigated diameters. In all cases, no damage was observed in the grouted mortar, and the slip values at the unloaded end were in the order of $10^{-2} \mathrm{~mm}$ (Fig. 3a and b). Specimens with the lowest values of the embedment length (i.e., $14 \cdot d_{b 1}$ and $10 \cdot d_{b 1}$ ) displayed a satisfying behavior too, with bar yielding, but in some cases splitting failure of concrete cover occurred before the bar failure (Fig. 3c). The opposite behavior was observed for control specimens, where bars were directly immersed in concrete: indeed, in this case, even the highest values of the embedment length (i.e., $26 \cdot d_{b 1}$ 
and $22 \cdot d_{b 1}$ ) were not sufficient to ensure the bar failure (Fig. 3d). Indeed, splitting failure occurred in one and two specimens over three, respectively for the configurations with $26 \cdot d_{b 1}$ and $22 \cdot d_{b 1}$ anchorage length. In the former case, the concrete failure occurred after the bar yielding, while in the latter case this happened only for one specimen, whereas in the other concrete failure occurred with the reinforcing bar still in the elastic state. It is also worth recalling that the concrete cover provided to the corrugated duct is quite low in this test geometry configuration, thus it is few confined. Despite this situation, the overall behavior of the connection is enhanced compared to the reference connections, and no slips were observed between the duct and concrete too. This behavior is own to the high mechanical interlock offered as bond mechanism by the corrugated duct to the concrete, due to the presence of ribs in the lateral surface of the ducts. Such results highlight the improved behavior offered by the grouted connection solution, able to guarantee a sufficient bar anchorage even at low embedment length values. Instead, the same behavior is not observed for specimens realized with the traditional concrete-to-steel anchorage, at low embedment lengths.

According to the above results, two anchorage length values were selected for the second part of the work to define the anchorage length of the longitudinal bars of the columns into the foundation, being 17 and $26 \cdot d_{b}$, i.e., the minimum value which ensured the bar failure for all the specimens tested, and the maximum value tested here, respectively.

\section{Experimental program}

The second part of the work deals with testing full scale RC column-to-foundation connections. The research program includes six full-scale RC columns having a square section, tested under combined cyclic lateral load and a constant axial load, with the aim to investigate the following aspects:

- Influence of the connection typology (cast-in-place or grouted);

- Role of different rebar diameters $\left(d_{b 1}=24 \mathrm{~mm}\right.$ and $\left.d_{b 2}=30 \mathrm{~mm}\right)$;

- Influence of bar anchorage length $\left(a_{L 1}=26 \cdot d_{b}\right.$ and $\left.a_{L 2}=17 \cdot d_{b}\right)$.

Hence, among the six specimens, four of them are grouted precast column-to-foundation, and two are realized as cast-in-place solution. Each specimen was identified according to the following notation:

- Cast-in-place (CIP) or grouted duct connections (G);

- Longitudinal rebars diameter $d_{b 1}=24 \mathrm{~mm}$ or $d_{b 2}=30 \mathrm{~mm}$;

- Only for $\mathrm{G}$ connections, bar anchorage length: $F$ for the full anchoring length $\left(a_{L 1}=\right.$ $\left.26 \cdot d_{b}\right), R$ for the reduced one $\left(a_{L 2}=17 \cdot d_{b}\right)$.

\subsection{Specimens geometry}

All the columns tested in this experimental program have the same geometry, consisting in a square section of $400 \mathrm{~mm}$ side and $2900 \mathrm{~mm}$ height, whereas foundation nuts have a constant dimension of base $\mathrm{x}$ length $=1400 \times 1800 \mathrm{~mm}$. Two different height values of 700 $\mathrm{mm}$ and $850 \mathrm{~mm}$ were adopted to ensure the anchorage of the protruding $d_{b 1}=24 \mathrm{~mm}$ and $d_{b 2}=30 \mathrm{~mm}$ rebars, respectively. Table 3 summarizes the characteristics of each specimen. 
Figure 4 shows the details of longitudinal and transverse reinforcement of the six columns. Steel reinforcement is designed according to NTC (2018), EC2 (2014) and EC8 (2014) to ensure a medium ductility class $(D C M)$. Concerning transverse reinforcement in the column, consisting in a double layer of $\Phi 10$ stirrups, it is worth noting that two regions were identified, the first with $100 \mathrm{~mm}$ spacing at the column base, and the second with $150 \mathrm{~mm}$ spacing. Figure 4 shows also the footprints of the $80 \mathrm{~mm}$ diameter corrugated ducts where the longitudinal bars are anchored. Instead, Figs. 5 and 6 show the lateral view of the specimens, along with the distribution of the transverse reinforcement in the column height, and the geometry of the connection between columns and foundation. Note that, for each specimen, the foundation was designed to remain elastic during the test execution.

\subsection{Material properties}

Specimens were casted adopting two different concrete strength classes for columns and foundations, i.e., C45/55 and C25/30 (nomenclature according to EC2 2014), respectively. The choice of adopting two strength classes is owned to the current engineering practice, where foundations have typically a reduced strength class (unless for peculiar durability issues) than elevation structures, and particularly, less than precast elements. Both columns and foundations were casted horizontally and cured in the laboratory without significant thermal excursions (in average, $\mathrm{T}=20 \pm 2{ }^{\circ} \mathrm{C}$ and $\mathrm{RH}=50 \pm 5 \%$ ). For each element, a single concrete batch was realized for the column and one for the foundation, hence the mechanical properties of concrete mixtures were experimentally measured through:

- 2 cubes (side of $150 \mathrm{~mm}$ ) to evaluate concrete cubic compressive strength at 28 days $f_{c, \text { cube }, 28 \text { days; }}$;
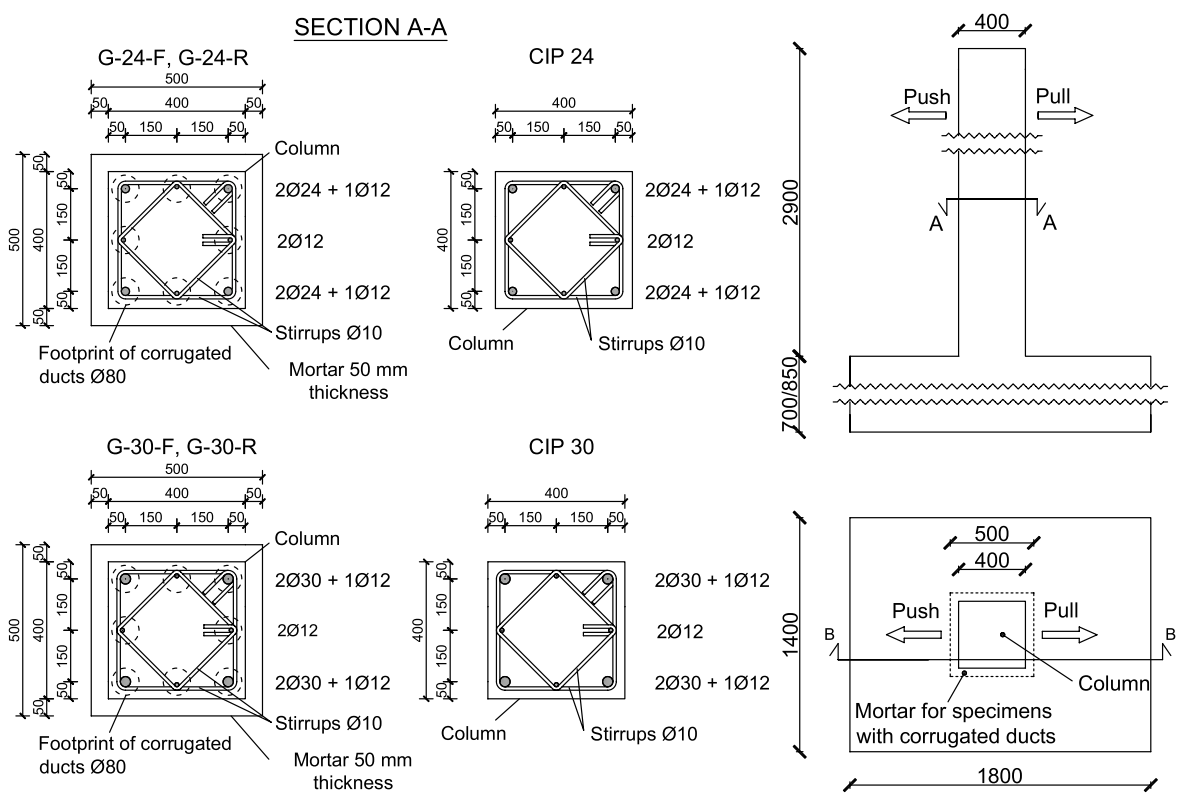

Fig. 4 Specimen geometry with reinforcement details (dimensions are in [mm]) 


\section{SECTION B-B}

G-24-F

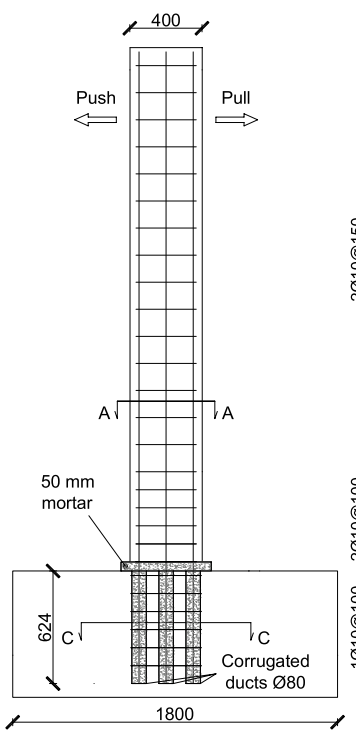

G-24-R

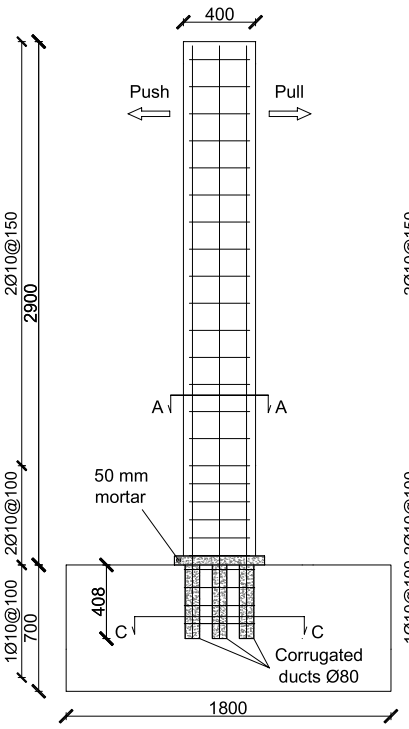

CIP 24

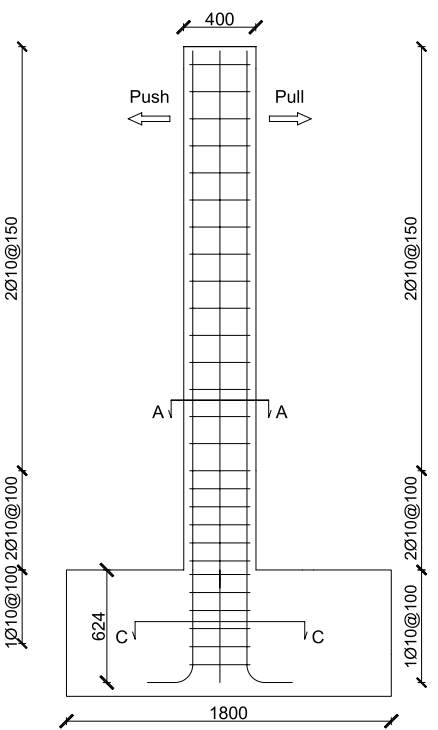

Fig. 5 Details of column-to-foundation connections for specimen G-24-F, G-24-R and CIP-24

\section{SECTION B-B}

G-30-F

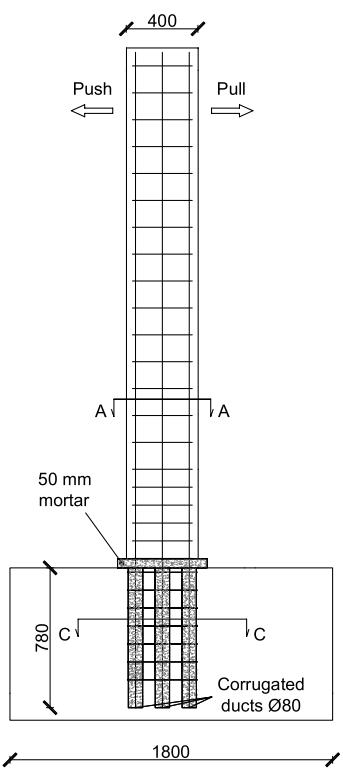

G-30-R

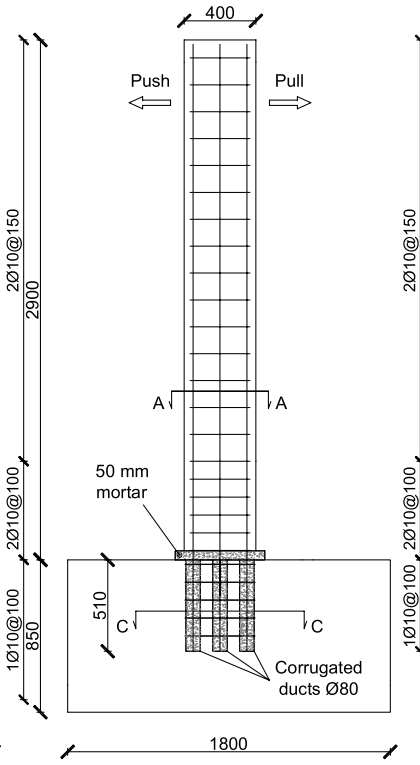

CIP 30

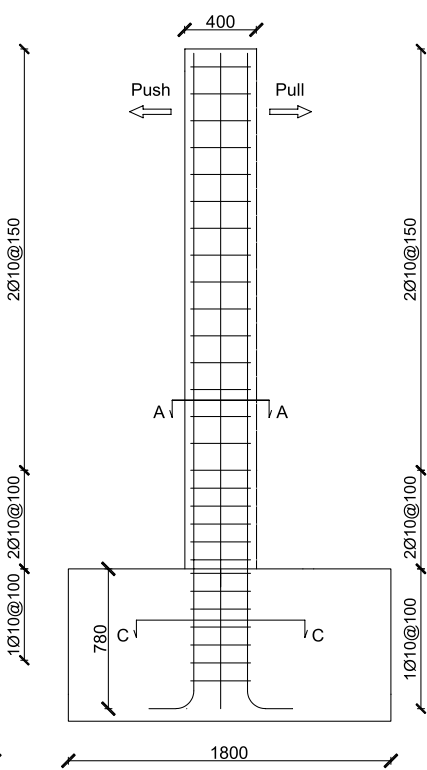

Fig. 6 Details of column-to-foundation connections for specimen G-30-F, G-30-R and CIP-30 
Table 3 Full-scale RC columns characteristics

\begin{tabular}{|c|c|c|c|c|c|c|c|c|}
\hline \multirow[t]{2}{*}{ \# } & \multirow[t]{2}{*}{ Specimen } & \multirow[t]{2}{*}{ Connection type } & \multicolumn{2}{|c|}{ Longitudinal reinforcement } & \multicolumn{2}{|c|}{$\begin{array}{l}\text { Transverse reinforce- } \\
\text { ment }\end{array}$} & \multicolumn{2}{|c|}{$\begin{array}{l}\text { Anchorage } \\
\text { length }\end{array}$} \\
\hline & & & Bars & Ratio $[\rho \%]$ & Bars & Spacing $[\mathrm{mm}]$ & {$[\mathrm{mm}]$} & $\mathrm{d}_{b}$ \\
\hline 1 & G-24-F & Grouted & $4 \Phi 24+4 \Phi 12$ & 1.41 & $\Phi 10$ & $100 / 150$ & 624 & 26 \\
\hline 2 & G-24-R & Grouted & $4 \Phi 24+4 \Phi 12$ & 1.41 & $\Phi 10$ & $100 / 150$ & 408 & 17 \\
\hline 3 & CIP-24 & Cast-in-place & $4 \Phi 24+4 \Phi 12$ & 1.41 & $\Phi 10$ & $100 / 150$ & - & - \\
\hline 4 & G-30-F & Grouted & $4 \Phi 30+4 \Phi 12$ & 2.05 & $\Phi 10$ & $100 / 150$ & 780 & 26 \\
\hline 5 & G-30-R & Grouted & $4 \Phi 30+4 \Phi 12$ & 2.05 & $\Phi 10$ & $100 / 150$ & 510 & 17 \\
\hline 6 & CIP-30 & Cast-in-place & $4 \Phi 30+4 \Phi 12$ & 2.05 & $\Phi 10$ & $100 / 150$ & - & - \\
\hline
\end{tabular}

- 4 cubes (side of $150 \mathrm{~mm}$ ) to evaluate concrete cubic compressive strength at time of specimen testing, i.e., at 40 days $f_{c, \text { cube }, 40 \text { days }}$;

- 2 cylinders $150 \times 300 \mathrm{~mm}(d \times h)$ to evaluate concrete tensile strength $f_{t}$ via Brazilian test;

- 3 cylinders $150 \times 300 \mathrm{~mm}(d \times h)$ to evaluate the secant modulus of elasticity $E_{c}$.

All cubes and cylinders were left curing at the same environmental conditions of the specimens. Table 4 lists the hardened concrete properties, tested according to EN 12,390 series. Note that the properties of CIP connections are slightly lower than those of precast elements, due to the differences in concrete casting protocols between cast-inplace operations and prefabrications.

Reinforcement bars were realized with B450C steel (NTC 2018). Table 5 lists the mechanical properties of the longitudinal rebars and stirrups, where $f_{y}$ represents the average yield strength, $f_{t}$ the average ultimate tensile strength, and $\epsilon_{t}$ is the average percentage elongation at maximum force.

The grouting high-performance mortar was tested both at 28 days and at the time of column testing, on six $40 \times 40 \times 160 \mathrm{~mm}$ prisms, according to EN 1015 series: its

Table 4 Mechanical property of hardened concrete

\begin{tabular}{|c|c|c|c|c|c|c|}
\hline & \multicolumn{6}{|l|}{ Column } \\
\hline & G-24-F & G-24-R & CIP-24 & G-30-F & G-30-R & CIP-30 \\
\hline$f_{c 28, \text { cube }}[\mathrm{MPa}]$ & 65.6 & 65.6 & 60.6 & 68.0 & 68.0 & 54.3 \\
\hline$f_{c 40, \text { cube }}[\mathrm{MPa}]$ & 71.4 & 67.5 & 62.3 & 73.5 & 78.0 & 60.5 \\
\hline$f_{t}[\mathrm{MPa}]$ & 4.4 & 4.1 & 5.5 & 4.2 & 5.1 & 4.4 \\
\hline \multirow[t]{3}{*}{$E_{c}[\mathrm{MPa}]$} & 42,034 & 41,527 & 38,173 & 40,236 & 39,400 & 36,738 \\
\hline & \multicolumn{6}{|c|}{ Foundation } \\
\hline & G-24-F & G-24-R & CIP-24 & G-30-F & G-30-R & CIP-30 \\
\hline$f_{c 28, \text { cube }}[\mathrm{MPa}]$ & 40.6 & 57.5 & 63.0 & 53.4 & 47.0 & 58.6 \\
\hline$f_{c 40, \text { cube }}[\mathrm{MPa}]$ & 50.6 & 60.5 & 63.8 & 57.0 & 60.6 & 60.5 \\
\hline$f_{t}[\mathrm{MPa}]$ & 4.1 & 4.5 & 5.5 & 5.6 & 4.4 & 4.9 \\
\hline$E_{c}[\mathrm{MPa}]$ & 34,122 & 37,099 & 39,828 & 37,360 & 35,579 & 38,021 \\
\hline
\end{tabular}


Table 5 Mechanical properties of reinforcing steel

\begin{tabular}{lllll}
\hline $\begin{array}{l}\text { Bar diameter } \\
{[\mathrm{mm}]}\end{array}$ & $f_{y}[\mathrm{MPa}]$ & $f_{t}[\mathrm{MPa}]$ & $\epsilon_{t}[\%]$ & $f_{t} / f_{y}[-]$ \\
\hline 10 & 526 & 623 & 12.0 & 1.18 \\
24 & 537 & 648 & 17.4 & 1.21 \\
30 & 572 & 673 & 19.8 & 1.18 \\
\hline
\end{tabular}

mechanical properties are listed in Table 6 , where $f_{c 28(40) \text {, cube }}$ is the compressive strength at 28 (or 40) days, and $f_{f 28(40) \text {, cube }}$ is mortar flexural strength at 28 (or 40 ) days.

\subsection{Fabrication of specimens}

Figure 7 shows the fabrication process for the grouted duct connections, which is mainly subdivided into three steps: first, the realization of the foundation, then column casting, and lastly the connection between the two elements. Commonly, foundation casting is directly made on site: in this phase, it is particularly important to ensure precise positioning of the corrugated ducts in the foundation nut. Furthermore, during concrete casting, both ends of the corrugated sleeves need to be protected to prevent the fresh concrete entry from the tube top and bottom (Fig. 7a and b).

Figure $7 \mathrm{c}$ shows the obtained foundation, where the eight ducts for anchoring the longitudinal column protruding bars are clearly shown. In this figure, the additional reinforcement needed to realize the testing layout is also visible, particularly the anchoring system to apply the axial compression to the column. Figure $7 \mathrm{~d}$ and $\mathrm{f}$ illustrate the phases for the realization of the precast column. In common practical applications, columns are precast in the factory and then moved to the site of construction. In this phase, special care to the positioning of longitudinal bars and stirrups is needed, particularly with those at the bottom of the column, where plastic hinge will be located. Finally, Fig. 7 g-7i show how the connection is completed through the addition of the high-performance mortar: first, some small steel plates are used in order to space the column from the foundation, and at the same time allowing the mortar to seal the connection without any voids. Then, the alignment is ensured by using some props, and lastly mortar is injected. Recall that a proper flowability and low shrinkage of the mortar is fundamental to ensure good bond with the steel bars.

\subsection{Test setup and instrumentation}

A cantilever scheme was adopted for testing the columns (see Fig. 8). The specimen was fixed to the strong reaction floor by using four prestressed steel threaded rods with $52 \mathrm{~mm}$ diameter, anchored in the foundation. The lateral displacement was applied at the top of the column by a hydraulic actuator with $+300 /-150 \mathrm{kN}$ capacity and a maximum displacement of \pm 160 $\mathrm{mm}$. The actuator is connected, at its ends, to the column and reaction frame with two pins, to allow the load remaining always perpendicular to the column longitudinal axis. A load cell,

Table 6 Mechanical properties of grouted mortar

\begin{tabular}{llll}
\hline$f_{c 28, \text { cube }}[\mathrm{MPa}]$ & $f_{c 40, \text { cube }}[\mathrm{MPa}]$ & $f_{f, 28}[\mathrm{MPa}]$ & $f_{f, 40}[\mathrm{MPa}]$ \\
\hline 61.60 & 63.18 & 8.64 & 9.41 \\
\hline
\end{tabular}


(a)

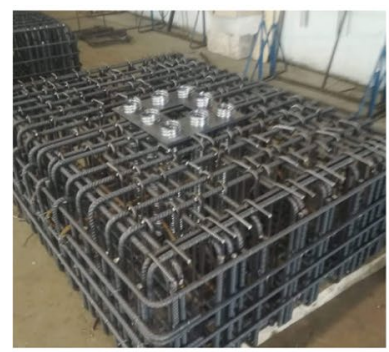

(d)

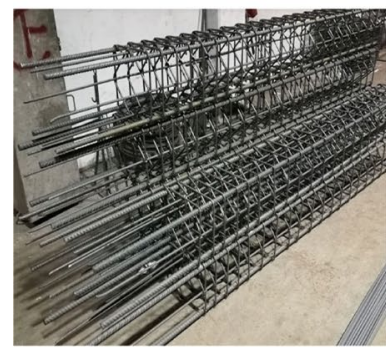

(g)

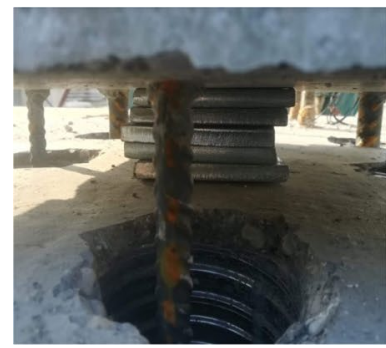

(b)

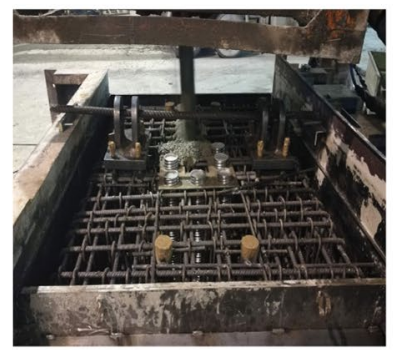

(e)

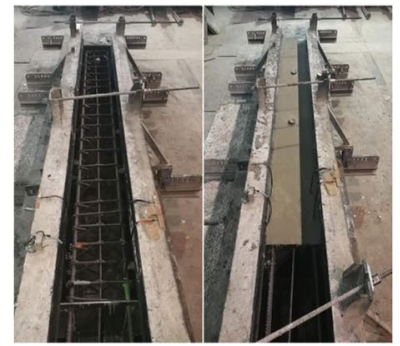

(h)

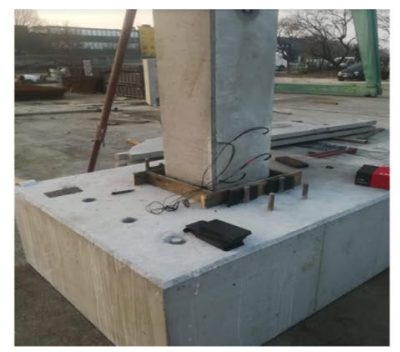

(c)

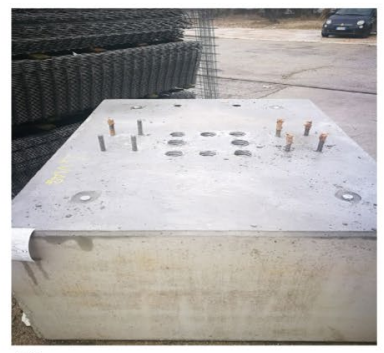

(f)

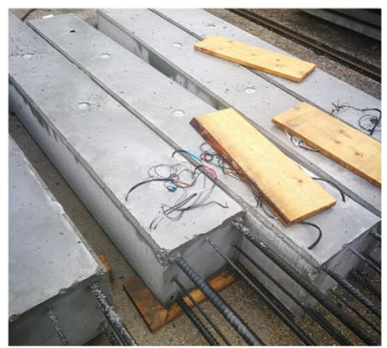

(i)

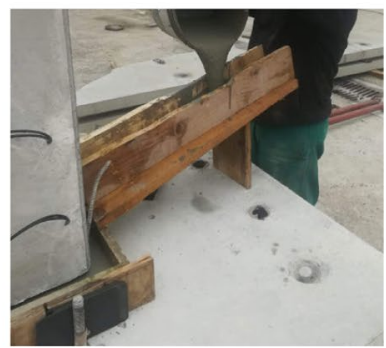

Fig. 7 Realization of precast grouted duct connections

which mounted a LVDT, was also adopted to directly correlate the imposed displacement to the measured force, and to evaluate and automatically correct, during the application of the loading history, the theoretical vs. the effective imposed displacement. Cyclic lateral load was applied via a quasi-static protocol: in detail, tests were performed under displacement control and the rate of lateral loading varied from $0.1 \mathrm{~mm} / \mathrm{s}$ for the lowest displacements cycles, to $0.8 \mathrm{~mm} / \mathrm{s}$ for the largest ones. Note that the first cycles were within the linear elastic response range. The test sequence was designed following the ACI 374.1-05 recommendations (ACI, 2014). The displacement history had the following characteristics:

- Three fully reversed cycles for each drift ratio, for assessing specimen performance under cyclic degradation at constant amplitude values;

- Displacements applied by gradually increasing the drift ratio $\delta$ until 5.5 (or 5) \%, considered as representative of the structural collapse (HAZUS, 2003).

Drift ratio $\delta$ is defined as the ratio between the imposed top displacement $\Delta$ and the column span $h$. For the three columns reinforced with $d_{b 1}=24 \mathrm{~mm}$ bars, the column span was 

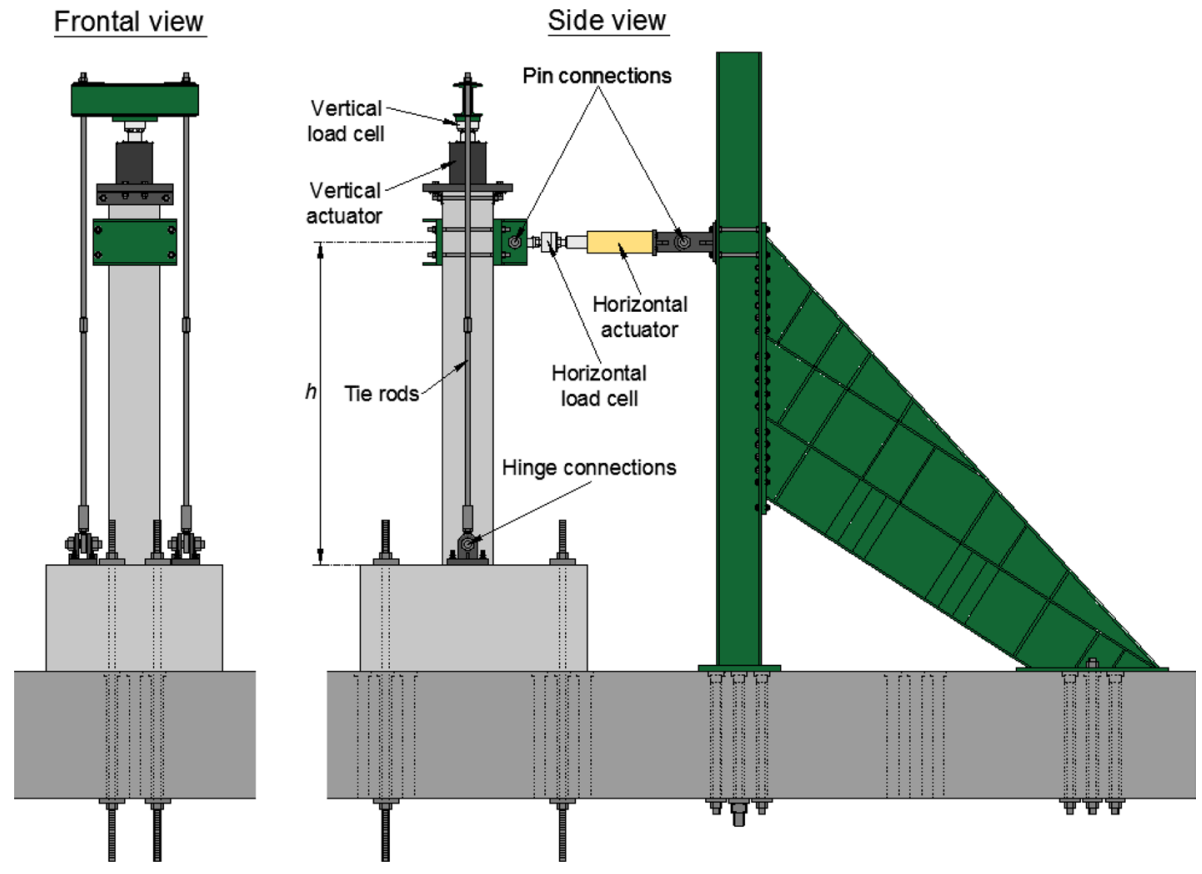

Fig. 8 Test set-up: frontal and side view

equal to $h=2500 \mathrm{~mm}$, while for other three specimens with $d_{b 2}=30 \mathrm{~mm}$ bars, $h$ was equal to $2550 \mathrm{~mm}$. These slightly different $h$ values resulted from the different foundation height (750 and $850 \mathrm{~mm}$, respectively for specimens with $d_{b 1}=24 \mathrm{~mm}$ and $d_{b 2}=30 \mathrm{~mm}$ ) and due to some limitations on the positioning of the hinge connected to the steel reaction frame for lateral load application. Figure 9 shows the imposed displacement history in terms of drift ratio $\delta$.

During the test a constant axial force, representative of a gravity loads regime compatible with that of the analyzed structural framing system, was applied on the column too, by using a $600 \mathrm{kN}$ hydraulic jack placed onto the column top. The jack allows to tension two tie roads hinged at the base of the column, immersed in the foundation, thus inducing a precompression to the column (see the details in Figs. 10 and 11). There, a load cell is also placed to acquire the applied load in the controller of the hydraulic system. The axial load was kept constant for all the testing time. For the set of columns reinforced with $d_{b 1}$ bars, a compressive load of $350 \mathrm{kN}$ was kept constant during the test, corresponding to a normalized design axial force $\left(v_{d}\right)$ of 0.07 . Instead, an axial force of $300 \mathrm{kN}$ was adopted for specimens with $d_{b 2}$ longitudinal rebars, corresponding to $v_{d}=0.06$. The design axial force $\left(v_{d}\right)$ was calculated as $v_{d}=N / A_{c} f_{c d}$, where $A_{c}$ is the column cross-section area, and $f_{c d}$ is the design compressive strength at the Ultimate Limit State (ULS) according to the Eurocode 2 (EC2 2004), evaluated as $f_{c d}=\alpha_{c c} f_{c k} / \gamma_{c}$, with $\alpha_{c c}=1$ for neglecting the long term effects on the compressive strength and $\gamma_{c}=1.5$.

Lastly, Fig. 10 illustrates the disposition of the measuring instruments. Four LVDTs (L1-L4) and 12 linear potentiometer sensors (P1-P12) were adopted at the base of the column, at four different heights to measure the column curvature. In addition, three wiretransducer (W1-W3) were used to capture the global behavior of the column. W1 measured 
(a)

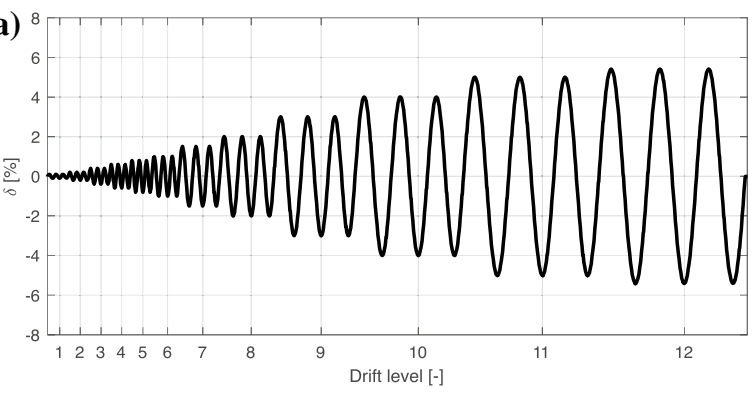

(b)

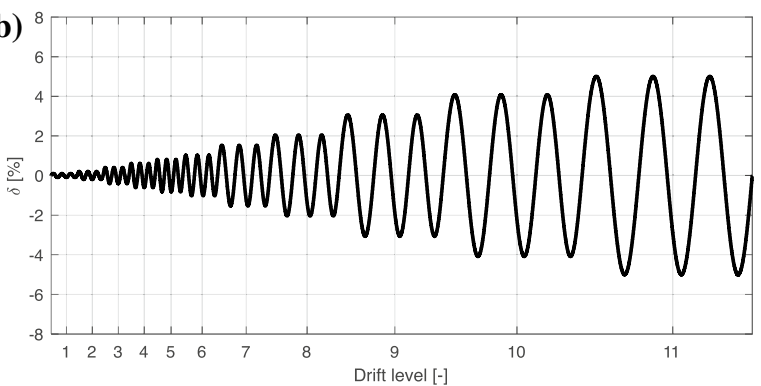

\begin{tabular}{cccc}
\hline Drift level & $\delta[\%]$ & $\Delta[\mathrm{mm}]$ & Cycles \\
\hline 1 & 0.1 & 2.5 & $1-3$ \\
2 & 0.2 & 5.0 & $4-6$ \\
3 & 0.4 & 10.0 & $7-9$ \\
4 & 0.6 & 15.0 & $10-12$ \\
5 & 0.8 & 20.0 & $13-15$ \\
6 & 1.0 & 25.0 & $16-18$ \\
7 & 1.5 & 37.5 & $19-21$ \\
8 & 2.0 & 50.0 & $22-24$ \\
9 & 3.0 & 75.0 & $25-27$ \\
10 & 4.0 & 100.0 & $28-30$ \\
11 & 5.0 & 125.0 & $31-33$ \\
12 & 5.5 & 137.5 & $34-36$ \\
\hline
\end{tabular}

\begin{tabular}{cccc}
\hline Drift level & $\delta[\%]$ & $\Delta[\mathrm{mm}]$ & Cycles \\
\hline 1 & 0.1 & 2.55 & $1-3$ \\
2 & 0.2 & 5.10 & $4-6$ \\
3 & 0.4 & 10.20 & $7-9$ \\
4 & 0.6 & 15.30 & $10-12$ \\
5 & 0.8 & 20.40 & $13-15$ \\
6 & 1.0 & 25.50 & $16-18$ \\
7 & 1.5 & 38.25 & $19-21$ \\
8 & 2.0 & 51.00 & $22-24$ \\
9 & 3.0 & 76.50 & $25-27$ \\
10 & 4.0 & 102.00 & $28-30$ \\
11 & 5.0 & 127.5 & $31-33$
\end{tabular}

Fig. 9 Lateral imposed displacement in terms of drift ratio $\delta$ : a for the set of columns G-24-F, G-24-R, CIP24 ; and $\mathbf{b}$ for the set of columns G-30-F, G-30-R, CIP-30

the column displacement at the same height where the horizontal jack is place, while W3 was placed at the top of the last level of potentiometers; W2 was in the middle. Finally, other six LVDTs (L5-L10) were used to evaluate that no slips occur between the foundation bottom and the reaction floor.

\section{Results and discussion}

This section discusses the experimental campaign results in terms of cracking pattern, failure modes, lateral load vs. drift curve, energy dissipation, curvature and plastic hinge localization.

\subsection{Cracking pattern and failure modes}

All the columns displayed similar cracking patterns, despite of the column longitudinal diameter bar size used. Columns with $d_{b 1}=24 \mathrm{~mm}$ were more damaged than columns with $d_{b 2}=30 \mathrm{~mm}$ rebars. Overall, comparing $\mathrm{G}$ and CIP columns, despite of the rebars diameter size, the main difference in terms of cracking patterns is mainly linked to a slightly less extension of the cracks in the columns height for the CIP configuration.

Regarding the columns reinforced with $d_{b 1}$ longitudinal rebars (G-24-F, G-24-R and CIP-24), the bending moment at the base of the column induced typical horizontal cracks with a consequent flexural damage. At the lowest drift value $(\delta=0.1 \%)$, columns 

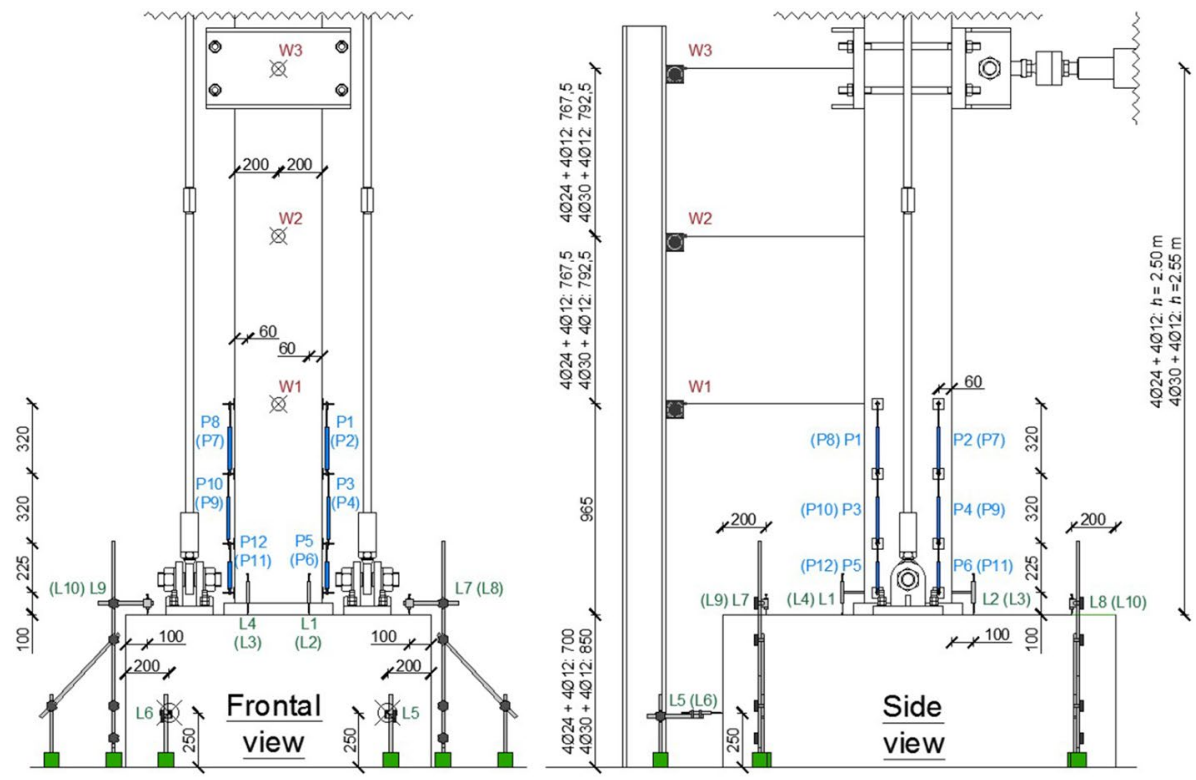

Fig. 10 Measuring instrumentation adopted in the experimental campaign

G-24-F
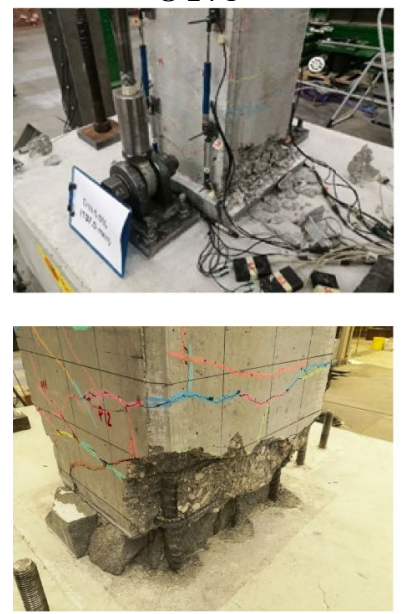

G-24-R
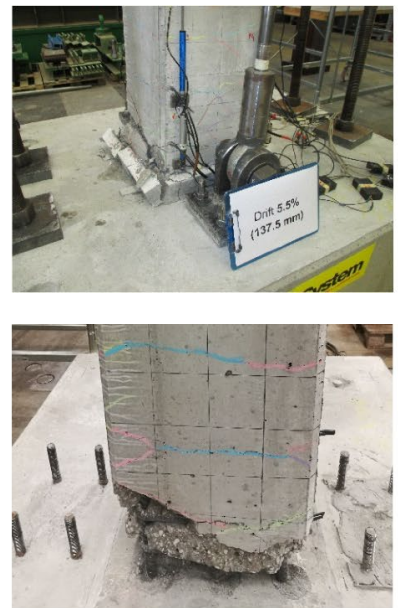

CIP 24
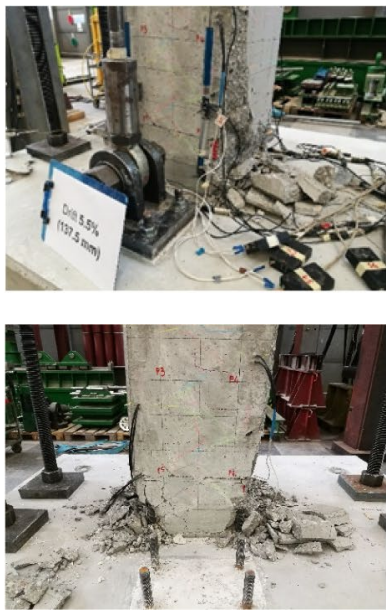

Fig. 11 Observed damage for $d_{b 1}$ specimens

behave perfectly elastically, with no cracks occurrence. The first cracks appeared during the second drift level for all the three specimens, and gradually increased along the height of the column up to $\delta=1.5 \%$, when the yield of the column longitudinal rebars occurred. During the highest displacement cycles, only few new cracks appeared, whereas the existing ones grew. From $\delta=2.0 \%$, damage mainly increased and concentrated at the base of column (i.e., $100 \div 150 \mathrm{~mm}$ from the bottom). In this region, in the 
grouted specimens G-24-F and G-24-R the high strength mortar collar started crushing; the same occurred for the concrete cover in column CIP-24, due to the high compressive stresses. At the end of the test, column G-24-F and G-24-R displayed the mortar collar almost fully crushed, as well as the concrete at the bottom of the column. Figure 11 shows the damaged specimens at the end of the test. For specimen G-24-F and G-24-R, no macro-damage was visible on the grouted connection. Furthermore, the intermediate longitudinal bar $\Phi 12$ in one side of column cross-section of specimen G-24-R and CIP24 , broke during the last drift level (failure recognized after a big noise during testing, with a sudden lateral load decrease, and later evaluated after specimen demolishing). In general, the three columns exhibited a comparable structural behavior, with a bending failure and the creation of a plastic hinge at the base of the column.

Concerning the columns reinforced with $d_{b 2}$ longitudinal rebars (G-30-F, G-30-R and CIP-30), also in this case they display comparable cracking pattern among them. During the first loading cycle $(\delta=0.1 \%)$ the columns behave elastically, and no cracks were detected. Later, cracks developed from $\delta=0.2 \%$ and gradually increased along the height of the column. At $\delta=1.5 \%$ the reinforcing bars started yielding. Figure 12 shows the damage pattern for the three columns. For specimen G-30-F and G-30-R, the mortar collar and the bottom of the column crushed for about $100 \mathrm{~mm}$. Similarly, in column CIP-30, splitting of concrete cover and concrete crushing occurred at the base of the column. The structural behavior of the three columns is also comparable in terms of extension of the most damaged part. In columns G-30-F and G-30-R no macro-damage was visible in the grouted connections.

\subsection{Horizontal load versus displacement}

The overall structural behavior of the specimens is here analyzed in terms of lateral load $(F)$ vs. top lateral drift ratio $(\delta)$ curves. Figures 13 and 14 show the experimental results for specimens with $d_{b 1}$ and $d_{b 2}$, respectively, whereas Table 7 lists all the significant points of the load vs. drift curve and the ductility index $\mu$ (defined in this section).
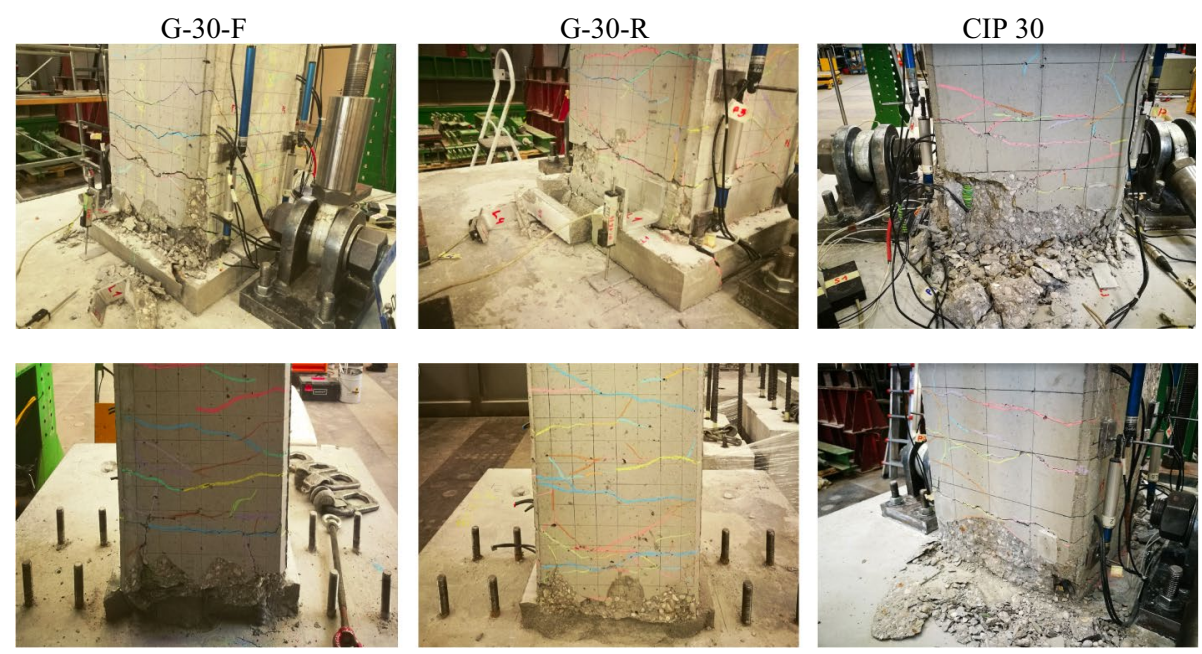

Fig. 12 Observed damage for $d_{b 2}$ specimens 


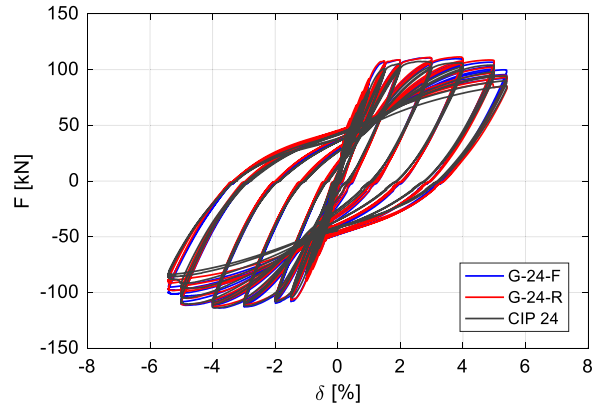

(a)

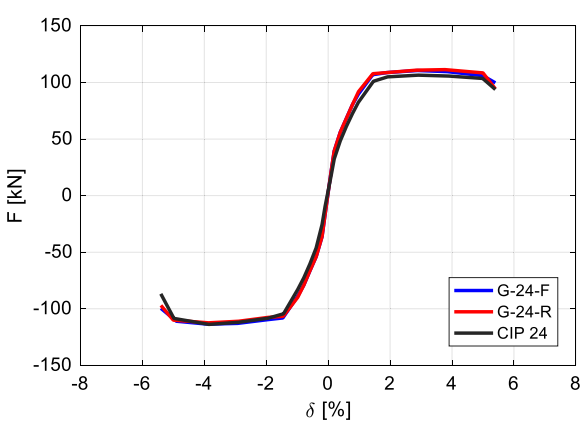

(b)

Fig. 13 Comparison of the three specimens with $d_{b l}$ in terms of horizontal load $(F)$ vs. lateral drift ratio $(\delta)$ : hysteretic cycles (a) and cycles envelope (b)

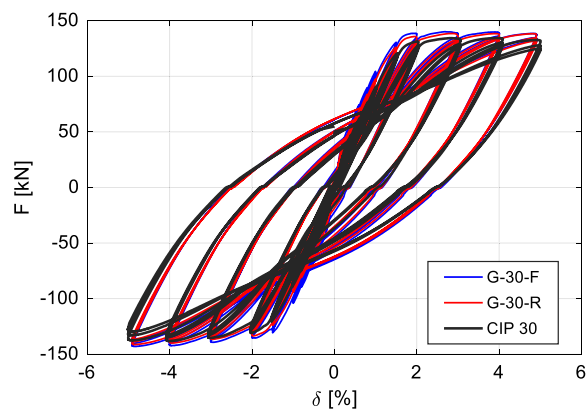

(a)

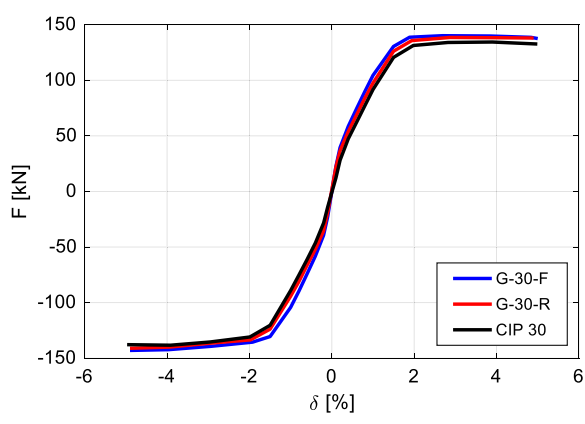

(b)

Fig. 14 Comparison of the three specimens with $d_{b 2}$ in terms of horizontal load $(F)$ vs. lateral drift ratio $(\delta)$ : hysteretic cycles (a) and cycles envelope (b)

Particularly, both hysteretic response and the envelope curves are represented. As main points of the load-drift curves, cracks opening, yielding, maximum attained load and ultimate conditions are highlighted. Specimens behave as linear elastic during early loading cycles, up to the development of the first cracks (cracks opening). Then, yielding is computed according to Park (1988), who suggested to consider the yield displacement of the equivalent elasto-plastic system with reduced stiffness computed as the secant stiffness at $75 \%$ of the ultimate lateral load of the real system. After the peak (maximum load), here two ultimate conditions were defined, one for specimen with $d_{b 1}=24 \mathrm{~mm}$ and another for specimens with $d_{b 2}=30 \mathrm{~mm}$. In the first case, the conventional ultimate state is defined at $90 \%$ of the peak force $F_{\max }$, i.e., $F_{u}=0.9 F_{\max }$, in accordance with Paulay (1989); therefore, it is possible to quantify the corresponding ultimate drift and displacement, too. In the second case, it was not possible to achieve a clear decrease of the load at the highest imposed displacement cycle: indeed,

the final cylic test pushed the structure up to an inter-storey drift of $5 \%$. Due to laboratory constraints linked to the attainment of the maximum stroke of the horizontal jack, hence, the ultimate displacement is defined exactly as $\delta=5 \%$, recognizing that this is a 
Table 7 Summary of experimental results for $d_{b 1}$ and $d_{b 2}$ specimens

\begin{tabular}{llllllll}
\hline & & $\mathrm{G}-24-\mathrm{F}$ & $\mathrm{G}-24-\mathrm{R}$ & $\mathrm{CIP}-24$ & $\mathrm{G}-30-\mathrm{F}$ & $\mathrm{G}-30-\mathrm{R}$ & CIP-30 \\
\hline Cracks opening & & & & & & & \\
Force, $F_{\text {cr }}[\mathrm{kN}]$ & $(+)$ & 38 & 37 & 35 & 36 & 34 & 22 \\
& $(-)$ & 37 & 37 & 34 & 36 & 31 & 23 \\
Drift, $\delta_{\text {cr }}[\%]$ & $(+)$ & 0.20 & 0.18 & 0.22 & 0.17 & 0.16 & 0.16 \\
& $(-)$ & 0.20 & 0.20 & 0.25 & 0.18 & 0.16 & 0.15 \\
Yielding state & & & & & & & \\
Drift, $\delta_{y}[\%]$ & $(+)$ & 1.16 & 1.20 & 1.24 & 1.41 & 1.45 & 1.53 \\
& $(-)$ & 1.16 & 1.20 & 1.28 & 1.48 & 1.52 & 1.59 \\
Maximum lateral load & & & & & & & \\
Force, $F_{\text {max }}[\mathrm{kN}]$ & $(+)$ & 110 & 111 & 107 & 140 & 139 & 134 \\
& $(-)$ & 114 & 112 & 113 & 143 & 141 & 138 \\
Drift, $\delta_{\text {max }}[\%]$ & $(+)$ & 2.92 & 3.85 & 2.72 & 2.71 & 2.80 & 3.95 \\
Ultimate state & $(-)$ & 3.83 & 3.86 & 3.92 & 5.00 & 5.00 & 4.00 \\
Force, $F_{u}[\mathrm{kN}]$ & & & & & & & \\
& $(+)$ & 99 & 100 & 96 & 138 & 138 & 133 \\
Drift, $\delta_{u}[\%]$ & $(-)$ & 102 & 101 & 102 & 143 & 141 & 137 \\
& $(+)$ & 5.42 & 5.32 & 5.35 & 5.00 & 5.00 & 5.00 \\
Ductility & $(-)$ & 5.38 & 5.35 & 5.15 & 5.00 & 5.00 & 5.00 \\
$\mu$ & & & & & & & \\
& $(+)$ & 4.67 & 4.43 & 4.31 & 3.54 & 3.45 & 3.27 \\
& $(-)$ & 4.64 & 4.46 & 4.02 & 3.36 & 3.27 & 3.11 \\
& Mean & 4.66 & 4.45 & 4.17 & 3.45 & 3.37 & 3.20 \\
\hline
\end{tabular}

lower bound state. Lastly, ductilty index $\mu$ represents the property of a lateral load resisting system to undergo large inelastic deformation during the post-peak branch, being the maximum load just slightly affected. The ductility index is thus defined as the ratio between the ultimate drift $\delta_{u}$, defined as above for $d_{b 1}$ and $d_{b 2}$ specimens, and the drift at the yielding point $\delta_{y}$ (Park, 1988; Park, 1989).

For the specimens with $d_{b 1}$ rebars, both analyzing the load-drift curves and the relevant points listed in Table 7, it is possible to state that the overall structural behavior is comparable. They display almost symmetric behavior in the push and pull conditions, mainly in terms of load values. The envelope curves in Fig. 13 are almost overlapping. Among the three specimens, the peak load of CIP-24 is slightly lower than the other two, probably due to the lower mechanical properties of concrete (see Table 4). Instead, a certain degree of variability occurs more visibly in terms of drift ratios, both analyzing the push and pull condition for a single specimen, and among different specimens for the same analyzed condition. This is due to several concomitant causes: very slight slippage of the foundation during the first pulling cycle that is maintained during the further loading; slight materials heterogeneity, that induce cracks predominant formation at one side; slight imperfection in the geometries. Furthermore, displacement values variability is also linked to the almost flat plastic branch of the envelope curve after peak, i.e., very small variations of the vertical load may occur in a large range of 
displacement values. Further, G-24-F has the highest ductility ratio, followed by G-24-R and lastly CIP-24.

Similar considerations can be made for columns reinforced with $d_{b 2}$ longitudinal bars. Figure 14 shows the load-drift curves for specimens G-30-F, G-30-R and CIP-30. Compared to previous samples, they display slightly larger unsymmetric results, mainly for the displacement values. However, overall, the behavior is considered sufficiently symmetric. For all these three specimens, the final cylic test pushed the structure up to an inter-storey drift of $5 \%$, without showing any tendencies to failure, thus demonstrating large ductility. Hence, for these samples, the ultimate condition at $\delta=5 \%$ was very close to that at maximum force $F_{\max }$, and specifically in two cases (negative drift of specimen G-30-F and G-30-R), they coincide. Similarly for specimens with $d_{b 1}$ bars, the specimen with the highest ductility index is the grouted duct connection with the longest anchorage length (G-30-F), followed by G-30-R and CIP-30.

\subsection{Energy dissipation}

Measurement of the dissipated energy is a meaningful index, independently from the ductility of a structural system (Germano et al., 2016). In this section, the energy dissipation capacity is computed for evaluating the capacity of the columns to absorb energy during the entire loading history. For each $i^{\text {th }}$ cycle, the dissipated energy $E_{d, i}$ can be computed as:

$$
E_{d, i}=\oint F(\Delta) d \Delta
$$

while the total energy dissipated during the test, up to the cycle $n$ can be easily computed as

$$
\Sigma E_{d, n}=\sum_{i}^{n} E_{d, i}
$$

Figures 15 and 16 show the dissipated energy specimens with $d_{b 1}$ and $d_{b 2}$ rebars, respectively, where both the dissipated energy for each $i^{\text {th }}$ cycle computed according to Eq. (1) and the cumulative dissipated energy during the entire load history, calculated according to Eq. (2) are displayed. For $d_{b 1}$ specimens, most of energy dissipation is concentrated starting from cycle 19, when the first yield of the longitudinal rebars occurred. High increments are visible starting from the 25 th cycle $(\delta=3 \%)$, 28th $(\delta=4 \%)$ and 31 st one $(\delta=5 \%)$, where a progressive yield of the longitudinal rebars is observed. Figure 15 shows that even under the energetic point of view, all specimens have a comparable structural behavior. Similarly, for $d_{b 2}$ specimens, Fig. 16 shows that most of the energy dissipation is concentrated at the end of the test, when the bars exceed the yielding point. It is worth noting that in the last drift levels, mainly $\delta=3 \%, \delta=4 \%$ and $\delta=5 \%$, the energy dissipation was stable for every repetition of each drift level, thus evidencing a good energy dissipation capacity.

\subsection{Curvature and plastic hinge computation}

This last section presents the curvature derivation along the height of the columns, aiming to compare the local behavior and to localize the plastic hinge. For each 


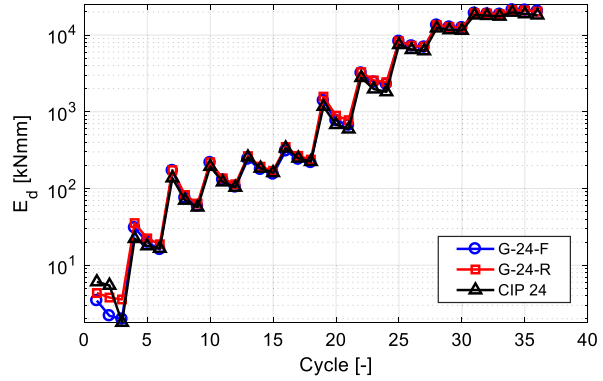

(a)

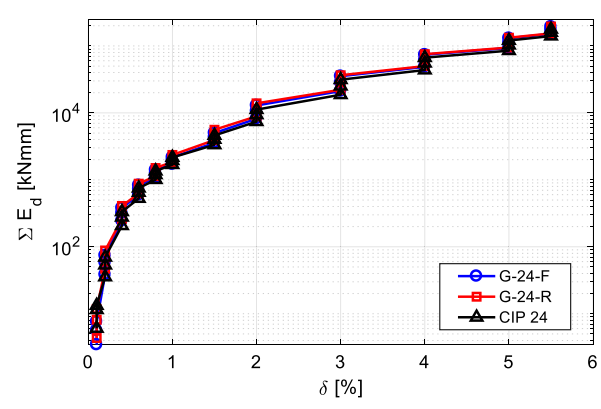

(b)

Fig. 15 Dissipated energy for each loading cycle (a), and cumulative dissipated energy for $d_{b 1}$ specimens (b)

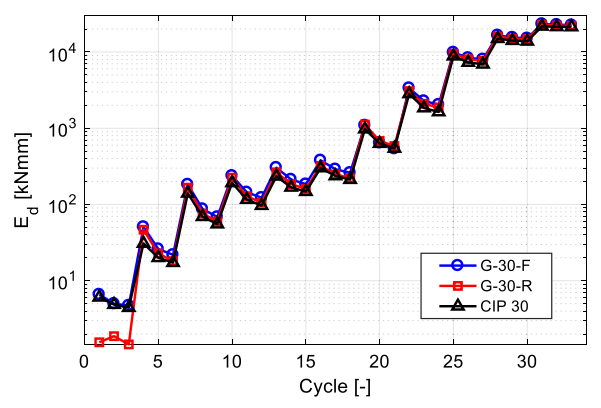

(a)

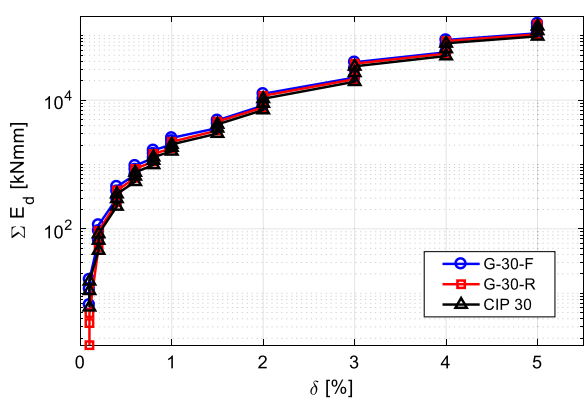

(b)

Fig. 16 Dissipated energy for each loading cycle (a), and cumulative dissipated energy for $d_{b 2}$ specimens (b)

displacement transducer position, the curvature was computed by dividing the numerical sum of compressive and tensile strains by the distance between each couple of displacement transducer (i.e., $280 \mathrm{~mm}$, see Fig. 10). This value was then plotted at the mid-span between successive pairs of dial gauges. In all cases, the curvature profiles were calculated at the first cycle of each drift level until $\delta=4 \%$, when concrete cracking made the instruments' readings no more reliable. Then, the curvature ductility factor $\mu_{\varphi}$ is computed according to Park (1988) and Park (1989) as:

$$
\mu_{\phi}=\phi_{u} / \phi_{y}
$$

where $\phi_{u}$ is the available ultimate curvature, obtained as the mean value of $\phi$ at $\delta= \pm 4 \%$, and $\phi_{y}$ is the yield curvature, computed from the conventional yield displacement $\Delta_{y}$ and column height $H$ :

$$
\phi_{y}=\frac{3 \Delta_{y}}{H^{2}}
$$


Figure 17 shows the curvature profile for the $d_{b 1}$ specimens; for both the push (positive drift) and pull (negative drift) directions, the curvature is presented in terms of mean value. Figure $17 \mathrm{a}, \mathrm{b}$ and $\mathrm{c}$ show respectively the curvature diagram for specimens G-24-F, G-24-R and CIP-24, while Fig. 17d plots a comparison of the curvature diagrams of the three specimens. The general trend for the curvature profiles indicates that curvature increases with the drift value; further, it decreases with the distance from the foundation. Most of curvature increase concentrates from drift $\delta=1.5 \%$. For all specimens, curvature profiles are quite symmetric with the highest values during pulling direction of the test. Until $\delta=3 \%$, the three profile are totally comparable, while for larger displacements, the curvature at the base of the CIP-24 specimen is higher than the others. The curvature ductility factor $\mu_{\varphi}$ for specimen G-24-F, G-24-R and CIP-24, is equal respectively to 10.9, 12.1 and 13.4.

Figure 18 shows the curvature profiles for $d_{b 2}$ specimens. Overall, the structural behavior of these specimens is similar to the previous ones, with curvatures concentrated in the last $500 \mathrm{~mm}$ at the base of the column and, slightly asymmetric for the higher drift levels. For G-30-F, G-30-R and CIP-30, curvature ductility factor $\mu_{\varphi}$ is equal respectively to 9.8 , 7.7 and 8.5.

Finally, columns are compared also in terms of plastic hinge localization, since the plastic hinge length is an important parameter to numerically simulate the nonlinear seismic response of the structural system. The plastic hinge region can be identified with the zone of the element where yielding of reinforcement and concrete crushing take place. Theoretical research by Priestley and Park (1987) has been the main approach used to investigate

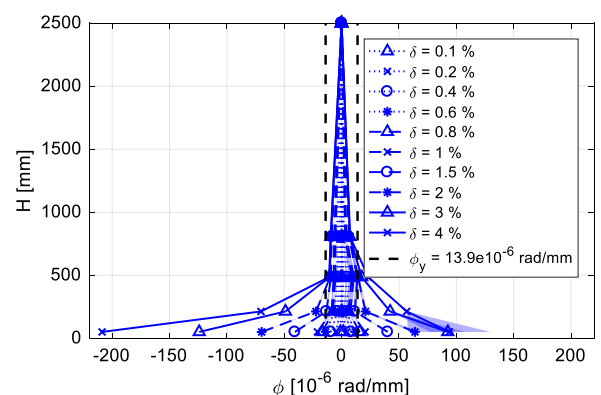

(a)

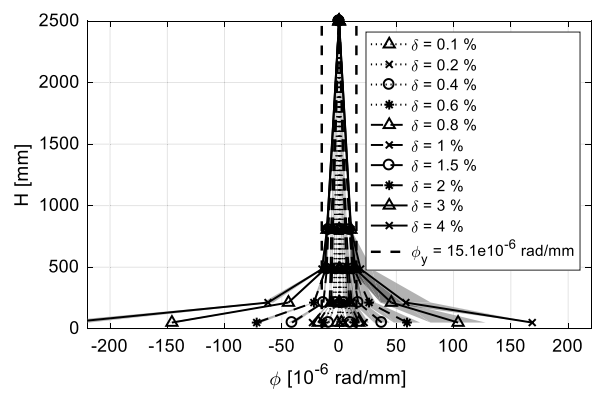

(c)

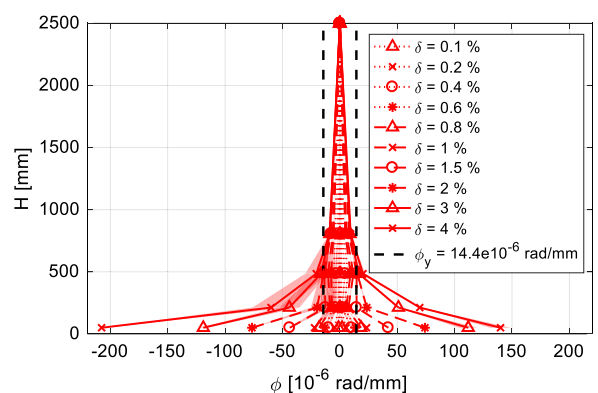

(b)

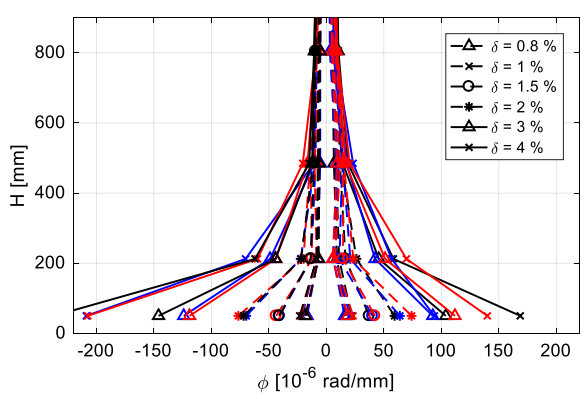

(d)

Fig. 17 Curvature profiles for $d_{b 1}$ specimens: a column G-24-F, b column G-24-R, c column CIP-24, d comparison between specimen G-24-F, G-24-R and CIP-24 


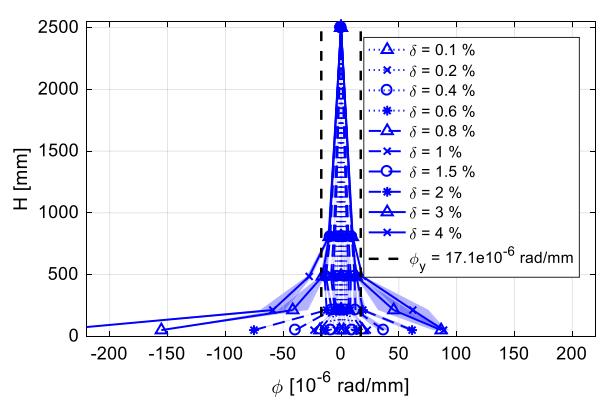

(a)

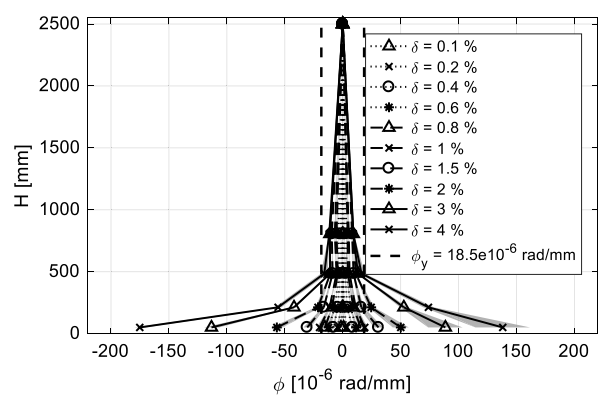

(c)

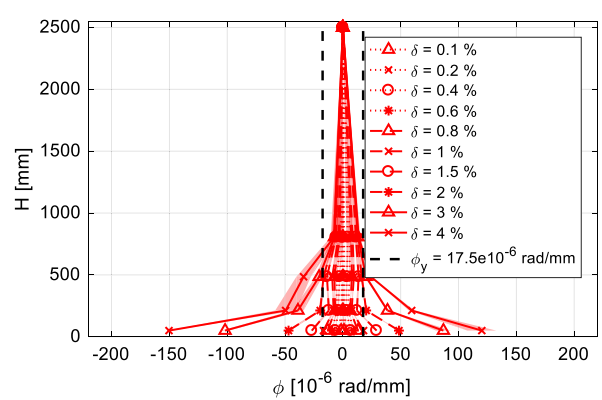

(b)

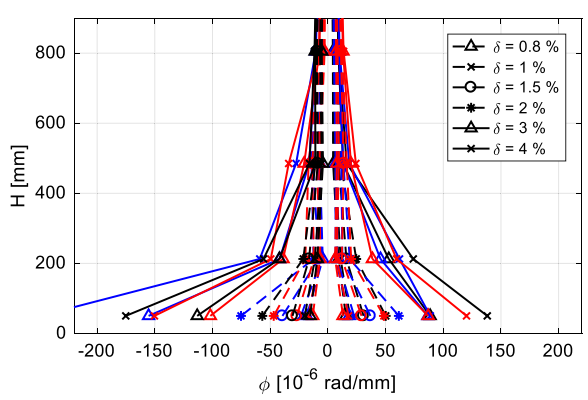

(d)

Fig. 18 Curvature profiles for $d_{b 2}$ specimens: a column G-30-F, b column G-30-R, c column CIP-30, d comparison between specimen G-30-F, G-30-R and CIP-30

the plastic hinge length. In this work, hence, the distribution of the curvature for an RC column was assumed as in Fig. 19. This distribution is composed by the yield curvature $\left(\varphi_{y}\right)$ linearly distributed along the column height and the rectangular plastic curvature $\left(\varphi_{p}\right)$, concentrated in the plastic zone. Typically, in the initial stages, $\left(M<M_{c r}\right)$, the response is elastic and linear. With an increase of the applied moment, cracking of the concrete reduces the flexural stiffness of the section, depending on the amount of reinforcement. For higher load levels, longitudinal bars begin to yield ( $\varphi_{y}$ and $M_{y}$, Fig. 19b), followed by concrete crushing $\left(\varphi_{u}\right.$ and $\left.M_{u}\right)$. A large increase in curvature and ductility normally occurs beyond the yield limit. The actual distribution of curvature at the ultimate load stage can be idealized into elastic and plastic regions, such that the total rotation $\left(\theta_{t}\right)$ over the column height can be divided into elastic $\left(\theta_{e}\right)$ and plastic $\left(\theta_{p}\right)$ rotations (Fig. 19c). The elastic rotation $\left(\theta_{e}\right)$ can be obtained using the curvature at yield, while the plastic rotation $\left(\theta_{p}\right)$ can be computed as the integral of the shaded area in Fig. 19c as:

$$
\theta_{p}=\int_{0}^{L_{y}}\left[\varphi(x)-\varphi_{y}(x)\right] d x
$$

where $L_{y}$ represents the length of the physical plastic length, corresponding to the real material yielding zone. In practical applications, it is convenient to refer to an equivalent plastic hinge $L_{p}$, derived by computing $\theta_{p}$ as the rectangular area $\phi_{p} \bullet L_{p}$. For computational purposes, the equivalent plastic hinge $L_{p}$ can be computed as (Jiang and $\mathrm{Wu}, 2015$ ): 
(a)

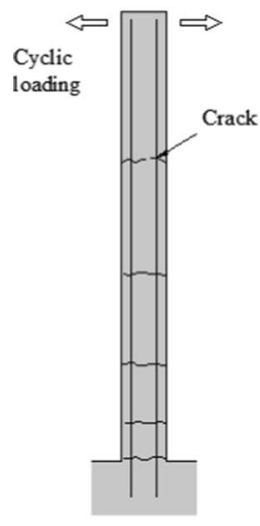

(b)

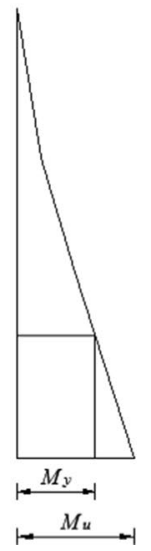

(c)

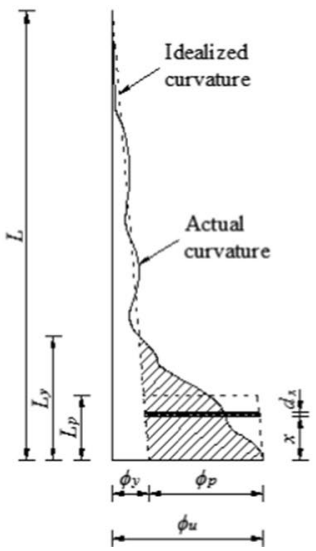

(d)

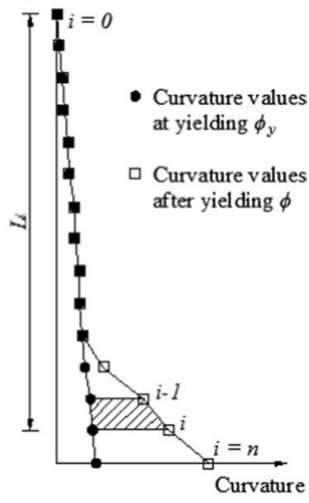

Fig. 19 Schematic curvature distribution along a RC member at ultimate stage: a RC member, b bending moment diagram, $\mathbf{c}$ curvature diagram and $\mathbf{d}$ model for the plastic hinge length $L_{P}$ computation

$$
L_{p}=2 L-2 \frac{\sum_{i=1}^{n} \Delta \theta_{p i} \frac{L_{i}+L_{i-1}}{2}}{\sum_{i=1}^{n} \Delta \theta_{p i}}
$$

where $\Delta \theta_{p i}$ is the shaded area from section $i-1$ to section $i$, as shown in Fig. 19d. This approach is particularly convenient since it does not require the definitions of the curvature and displacements at the ultimate point, that could significantly vary in relation to the approach followed for its quantification (Park 1988, 1989; Chai et al. 1991; Jiang and Wu, 2015) and may not be properly identified in an experimental test. This is particularly true also referring to the present experimental campaign, where two ultimate condition definitions were adopted, depending on the specimen types.

Figure 20 shows the plastic hinge length computed for the $d_{b 1}$ (Fig. 20a) and $d_{b 2}$ specimens (Fig. 20b). In both cases, $L_{p}$ is computed for drift levels higher than $\delta=2 \%$, i.e., when the columns displayed the plastic phase. For the highest drift levels $(\delta=3 \%$ and $\delta=4 \%)$, the plastic hinge at the base of the column is fully developed, and $L_{p}$ tends to stabilize. Furthermore, the computed $L_{p}$ values are compared with the one proposed by the Eurocode 8 (EC8), Eq. (A.9), developed for members with detailing for earthquake resistance and without lapping of longitudinal bars in the vicinity of the section where yielding is expected, and for cyclic loading, as:

$$
L_{p}=\frac{L_{V}}{30}+0.20 h+0.11 \frac{d_{b L} f_{y}(\mathrm{MPa})}{\sqrt{f_{c}(\mathrm{MPa})}}
$$

where $h$ is the cross-section depth of the member and $d_{b L}$ is the (mean) diameter of the tension reinforcement bars. Figure 20 shows how for both the tested bars diameter ( 24 and $30 \mathrm{~mm}$ ) there are no significant discrepancies among the specimens with full and reduced anchorage lengths. Furthermore, the plastic hinge length computed with Eq. (7) well predicts the obtained values. For both rebars diameters, $L_{p}$ of the cast-in-place specimens is slightly shorter than the one of the precast specimens, maybe due to the stiff restrain introduced by the small steel plates adopted for positioning the columns (Fig. 7g). However, this difference seems to be negligible and not influencing the overall structural behavior of the tested connections. 


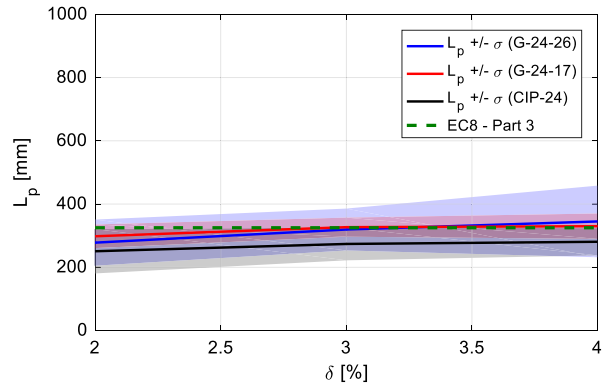

(a)

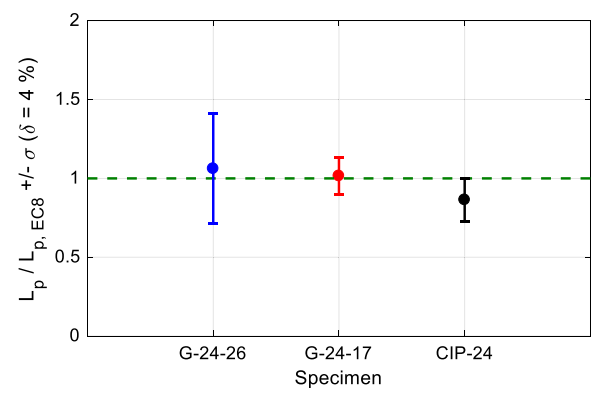

(c)

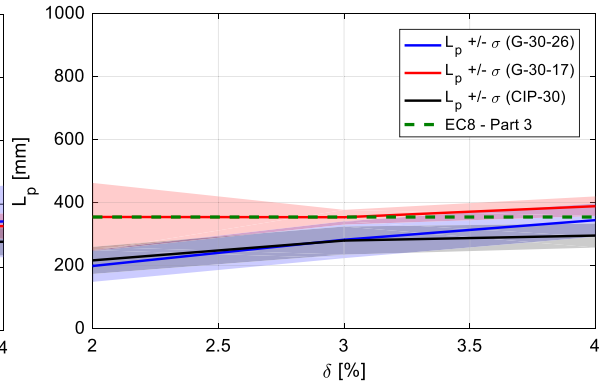

(b)

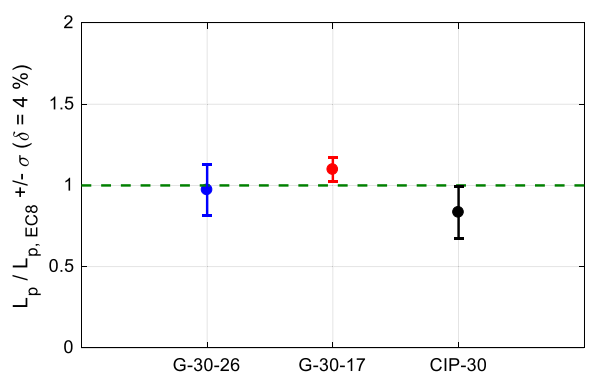

(d)

Fig. 20 Plastic hinge lengths for $d_{b 1}$ (a) and $d_{b 2}$ specimens (b). Comparison of $L_{P}$ computed at drift level $\delta$ $=4 \%$ and with the EC8 formula for $d_{b 1}(\mathbf{c})$ and $d_{b 2}$ specimens (d)

\section{Conclusions}

This paper presented the results of an experimental campaign that allowed investigating the structural behavior of full-scale precast concrete foundation-to-column connections. The connection system tested here has steel ducts positioned in the foundation block, and longitudinal reinforcement bars, protruding from the column, anchored in the foundation nut by grouted high performance mortar. The connections tested in the experimental campaign seemed particularly efficient, since the steel ducts are well confined by the massive concrete cast of the foundation. Compared to similar technologies, this connection type avoids some specific detailing that are typical of other precast connection technologies (e.g. bar couplers, bolted and/or welded connections, detailing for confinement). On the other hand, this connection type is less immediate than others, since it requires a precise implementation at the building site, and a careful column handling in order to avoid localized damage to the protruding bars during the on-site lifting and installation phases. According to the experimental evidences obtained in this work, it is possible to draw the following conclusions:

- A good performance of the connection was observed: indeed, stable and symmetric hysteretic behavior was observed up to the final drift ratios, totally comparable with the cast-in-place solution. The same applies for ductility, dissipated energy and curvature profile, similar for both precast and cast-in-place specimens; 
- All specimens showed a ductile flexural failure with the formation of the plastic hinge at the base of the column. Concrete and mortar crushing occurred at the last drift levels, and in two cases the tensile failure of a longitudinal reinforcement bar took place;

- The two embedment lengths values used in this work seem sufficient to anchor the column longitudinal rebars into the foundation, to guarantee the same structural behavior of the cast-in-place solution under cyclic loading. However, further studies are needed for investigating the joint seismic overstrength, even considering other failure modes and in presence of $P-\Delta$ effects;

- The plastic hinge length was evaluated and its value was compared with that proposed by the Eurocode 8 formulation, showing a maximum discrepancy of about $16 \%$. This is particularly useful since the same structural model developed for the cast-in-place solution can be used also for modelling precast structures that include this connection type;

- In detail, for both $24 \mathrm{~mm}$ and $30 \mathrm{~mm}$ rebars diameter, the plastic hinge length of the cast-in-place specimens resulted slightly shorter than in reference specimens. This can be probably due to the small steel plates adopted for supporting the column in the mortar casting phase that provide a stiff thick element between the column and the foundation.

Acknowledgements The present work discusses the experimental behavior of the column-to-foundation connection of the precast system developed by NUOVA TESI SYSTEM S.r.l. who realized the tested specimens and is gratefully thanked. The authors would like also to thank Eng. Giovanni Gobbi and Eng. Enrico Rovizzi for their help during testing operations.

Author contributions LH: conceptualization, methodology, investigation, formal analysis, writing—original draft, writing—review and editing; MAZ: conceptualization, methodology, investigation, writing—original draft, writing - review and editing, supervision; FF: conceptualization, methodology, investigation, formal analysis, writing — original draft, writing — review and editing, supervision; KT: investigation; CP: funding acquisition, supervision. All authors read and approved the final manuscript.

Funding Open access funding provided by Università degli Studi di Padova within the CRUI-CARE Agreement. This study was funded by NUOVA TESI SYSTEM S.r.l. who financed the realization of the specimens and supported costs for the execution of the experimental campaign.

Data availability All data will be available on request to the Authors.

\section{Declarations}

Conflict of interest The authors declare that they have no potential conflict of interest.

Open Access This article is licensed under a Creative Commons Attribution 4.0 International License, which permits use, sharing, adaptation, distribution and reproduction in any medium or format, as long as you give appropriate credit to the original author(s) and the source, provide a link to the Creative Commons licence, and indicate if changes were made. The images or other third party material in this article are included in the article's Creative Commons licence, unless indicated otherwise in a credit line to the material. If material is not included in the article's Creative Commons licence and your intended use is not permitted by statutory regulation or exceeds the permitted use, you will need to obtain permission directly from the copyright holder. To view a copy of this licence, visit http://creativecommons.org/licenses/by/4.0/.

\section{References}

ACI 374.1-05 (2014) Acceptance criteria for moment frames based on structural testing and commentary 
Al-Jelawy H, Haber Z, Mackie K (2017) Grouted splice precast column connections with shifted plastic hinging. In: 16th World conference on earthquake-16WCEE 2017, Santiago Chile, January 9-13

Belleri A, Riva P (2012) Seismic performance and retrofit of precast concrete grouted sleeve connections. Precast/Prestressed Concr Inst J 57(1):97-109

Belleri A, Brunesi E, Nascimbene R, Pagani M, Riva P (2015) Seismic performance of precast industrial facilities following major earthquakes in the Italian territory. J Perform Constr Facil 29(5):04014135

Buratti N, Bacci L, Mazzotti L (2012) Seismic behaviour of grouted sleeve connections between foundations and precast columns. In: 15th World conference of earthquake engineering (WCEE), Lisbon, Portugal, September 24-28, paper no. 1525

Buratti N, Minghini F, Ongaretto E, Savoia M, Tullini N (2017) Empirical seismic fragility for the precast RC industrial buildings damaged by the 2012 Emilia (Italy) earthquakes. Earthq Eng Struct Dyn 46:2317-2335

Camnasio E, Jurina L, Radaelli EO, Bianco L, Montenovo S (2017), Indagini sperimentali sul collegamento bullonato pilastro-fondazione per applicazioni sismiche, IV Convegno di Ingegneria forense, VII Convegno su Crolli, Affidabilità Strutturale, Consolidamento, Politecnico di Milano, 14-16 settembre 2017

Caputo AC, Kalemi B, Paolacci F, Corritore D (2020) Computing resilience of process plants under Na-Tech events: Methodology and application to sesmic loading scenarios. Reliab Eng Syst Safety 195:106685

Chai Y, Priestley M, Seible F (1991) Seismic retrofit of circular bridge columns for enhanced flexural performance. ACI Struct J 88(5):572-584

Dal Lago B, Toniolo G, Lamperti Tornaghi M (2016) Influence of different mechanical column-foundation connection devices on the seismic behaviour of precast structures. Bull Earthq Eng 14:3485-3508

Einea A, Yamane T, Tadros MK (1995) Grout-filled pipe splices for precast concrete construction. Precast/ Prestressed Concrete Institute, January-February 1995

EC2 (EN 1992) (2014) Eurocode 2: Design of concrete structures

EC8 (EN 1998) (2014) Eurocode 8: Design provisions for earthquake resistance of structures

Elliott KS (2017) Precast concrete structures, 2nd edn. CRC Press, Boca Raton

Elsayed M, Nehdi ML (2017) Experimental and analytical study on grouted duct connections in precast concrete construction. Mater Struct 50:198

Elsayed M, Ghrib F, Nehdi ML (2018a) Experimental and analytical study on precast concrete dowel connections under quasi-static loading. Construction Building Material 168:692-704

Elsayed M, Nehdi ML, Provost-Smith DJ, Eissa OS (2018b) Exploratory investigation of grouted bar-induct connections under direct tensile load. Construction Building Material 183:311-324

EN 1015-11:2019 (2019) Methods of test for mortar for masonry. Determination of flexural and compressive strength of hardened mortar

EN 12390 (2019) (2019) Testing hardened concrete

Fagà E, Bianco L, Bolognini D, Nascimbene R (2010) Comparison between numerical and experimental cyclic response of alternative column to foundation connections of RC precast structure. In: 3rd International FIB congress and exhibition, May 29th-June 2nd, Washington DC

Fan JJ, Feng DC, Wu G, Hou S, Lu Y (2020) Experimental study of prefabricated RC column-foundation assemblies with two different connection methods and using large-diameter reinforcing bars. Eng Struct 205:110075

Germano F, Tiberti G, Plizzari G (2016) Experimental behavior of SFRC columns under uniaxial and biaxial cyclic loads. Compos B 85:76-92

Guo H, Zhang J, Wang C (2020) Experimental study on influence of connection defects on joint strength of half-grouted sleeve splicing of rebar, Adv Civil Eng, ID 5389861

Haber ZB, Saiidi MS, Sanders DH (2012) Seismic performance of precast columns with mechanically spliced column-footing connections. ACI Struct J 111(3):639-650

Hofer L, Zanini MA, Faleschini F, Pellegrino C (2018) Profitability analysis for assessing the optimal seismic retrofit strategy of industrial productive processes with business-interruption consequences. J Struct Eng 144(2):4017205

HAZUS-MH MR4 (2003) Multi-hazard loss estimation methodology- Earthquake model. Dept. of Homeland Security Emergency Preparedness and Response Directorate Federal Emergency Management Agency, Washington, DC

Jiang C, Wu YF (2015) Variation of plastic hinge length for RC column. In: Proceedings of the The 12th International symposium on fiber reinforced polymers for reinforced concrete structures (FRPRCS-12) \& The 5th Asia-Pacific Conference on Fiber Reinforced Polymers in Structures (APFIS-2015), Joint Conference, 14-16 December 2015, Nanjing, China

Liu Y, Zhou B, Cai J, Lee DSH, Deng X, Feng J (2018) Experimental study on seismic behavior of precast concrete column with grouted sleeve connections considering ratios of longitudinal reinforcement and stirrups. Bull Earthq Eng 16:6077-6104 
Liu Y, Li X, Zheng X, Song Z (2020) Experimental study on seismic response of precast bridge piers with doublegrouted sleeve connections. Eng Struct 221:111023

Matsumoto EE, Waggoner MC, Kreger ME, Vogel J, Wolf L (2008), Development of a precast concrete cbent-cap system, Precast/Prestressed Concrete Institute, May-June 2008

Minghini F, Ongaretto E, Ligabue V, Savoia M, Tullini N (2016) Observational failure analysis of precast buildings after the 2012 Emilia earthquakes. Earthq Struct 11(2):327-346

Nocera F, Gardoni P (2019) A ground-up approach to estimate the likelihood of business interruption. Int J Disaster Risk Reduct 41:101314

NTC (2018) DM 17/01/2008: Norme Tecniche per le Costruzioni (in Italian)

Negro P, Toniolo G (2012) Design guidelines for connections of precast structures under seismic actions. EUR—Scientific and Technical Research Reports. JRC Publication No. JRC71599. Publications Office of the European Union

Park R (1988) State-of-the-art report: ductility evaluation from laboratory and analytical testing. In: Proceedings of 9th World conference on earthquake engineering, vol. 8, 1988. p. 605-616

Park R (1989) Evaluation of ductility of structures and structural assemblages from laboratory testing. Bullet New Zealand Natl Soc Earthq 22(3):155-166

Paulay T (1989) Equilibrium criteria for reinforced concrete beam-column joints. ACI Struct J 86(6):635-643

Philippi DJ, Hegemier GA (2013) Use of mechanical couplers in concrete columns. In: Architectural Engineering Conference 2013, April 3-5, 2013 I State College, Pennsylvania, United States

Popa V, Papurcu A, Cotofana D, Pascu R (2015) Experimental testing on emulative connections for precast columns using grouted corrugated steel sleeves. Bull Earthq Eng 13(8):2429-2447

Priestley MJN, Park R (1987) Strength and ductility of concrete bridge columns under seismic loading. ACI Struct J 84(1):61-76

RILEM/CEB/FIP (1982) Recommendations on reinforcement steel for reinforced concrete. Revised edition of: RC5 bond test for reinforcement steel: (1) Beam test, CEB News 61, Paris, France

RILEM/CEB/FIP (1983) Recommendations on reinforcement steel for reinforced concrete. Revised edition of: RC6 bond test for reinforcement steel: (2) Pull-out test, CEB News 73, Lausanne, Switzerland

Saisi A, Toniolo G (1998) Precast r.c. columns under cyclic loading: an experimental programme oriented to EC8. Studies and researches, F.lli Pesenti Master school. Politecnico di Milano 19:373-414

Savoia M, Buratti N, Vincenzi L (2017) Damages and collapses in industrial precast buildings after the 2012 Emilia earthquake. Eng Struct 137:162-180

Seifi P, Henry RS, Ingham JM (2019) In-plane cyclic testing of precast concrete wall panels with grouted metal duct base connections. Eng Struct 184:85-98

Sezen H, Whittaker AS (2006) Seismic performance of industrial facilities affected by the 1999 Turkey earthquake. J Perform Constr Facil 20(1):28-36

Tullini N, Minghini F (2016) Grouted sleeve connections used in precast reinforced concrete constructionexperimental investigation of a column-to-column joint. Eng Struct 127:784-803

Tullini N, Minghini F (2020) Cyclic test on a precast reinforced concrete column-to-foundation grouted duct connection. Bull Earthq Eng 18:1657-1691

Wang R, Ma B, Chen X (2021) Seismic performance of pre-fabricated segmental bridge piers with grouted splice sleeve connections. Eng Struct 229:111668

Xu Y, Zeng Z, Wang Z, Ge J (2021) Experimental studies of embedment length of precast bridge pier with socket connection to pile cap. Eng Struct 233:111906

Yanev P (1989) Performance of industrial facilities. Earthquake Spectra 5(3):101-113

Zhang G, Han Q, Xu K, Du X, He W (2021) Experimental investigation of seismic behavior of UHPC-filled socket precast bridge column-foundation connection with shear keys. Eng Struct 228(1):111527

Zheng LX (1996) Grouted precast concrete column connections under reversed cyclic bending and compression. ACI Struct J 93(3):247-256

Zhou Y, Ou YC, Lee GC (2017) Bond-slip responses of stainless reinforcing bars in grouted ducts. Eng Struct 141:651-665

Publisher's Note Springer Nature remains neutral with regard to jurisdictional claims in published maps and institutional affiliations. 